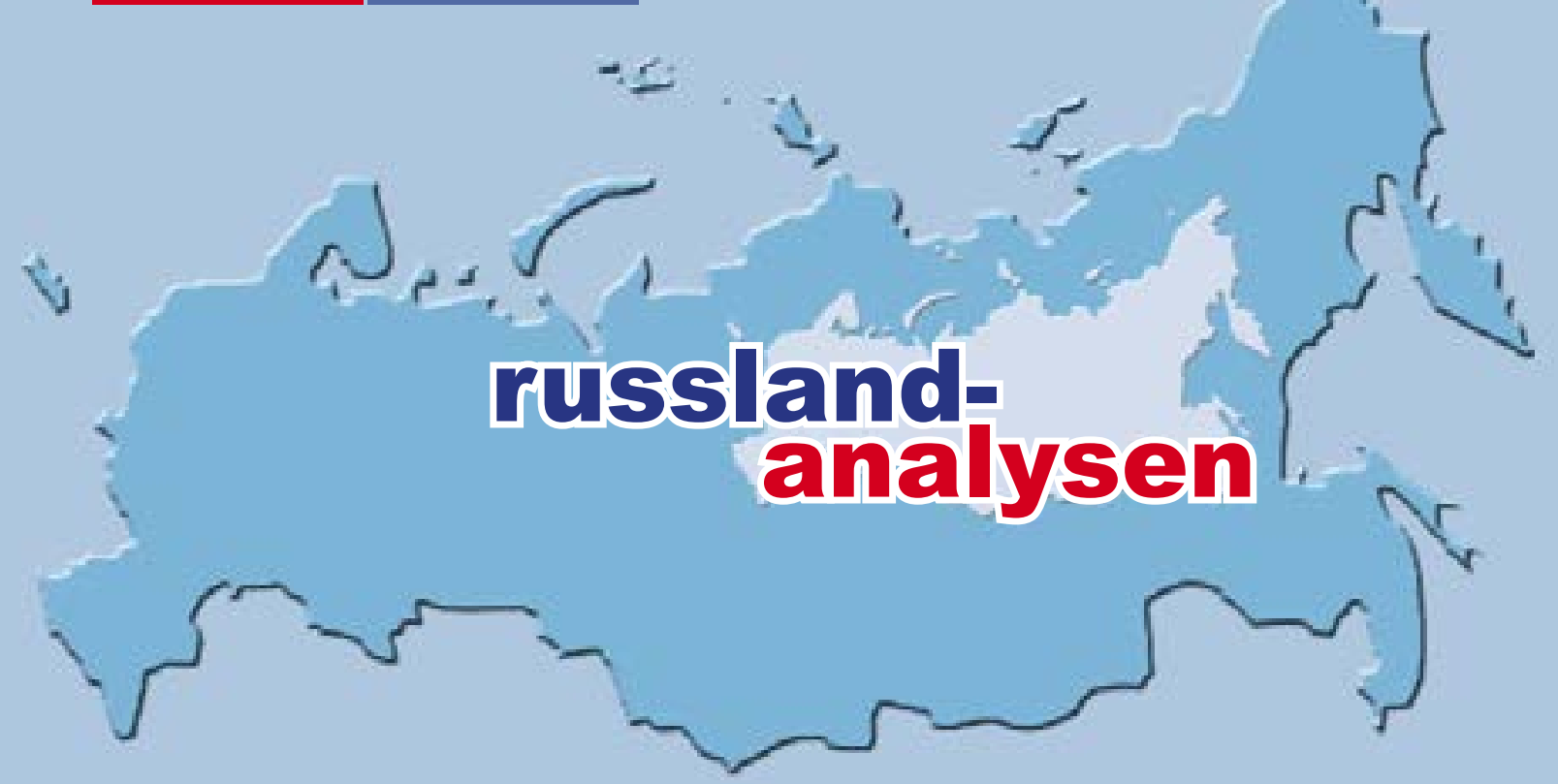

http://www.laender-analysen.de/russland/

\title{
UNTERNEHMENSKULTUR(EN) IN RUSSLAND
}

- ANALYSE

Gefangen in Informalität

Kleine und mittlere Unternehmen im russischen Kapitalismus

Alexandra Vasileva, Amsterdam

ANALYSE

Importierte Rechtssicherheit

Ursachen und Perspektiven der Nutzung ausländischen Rechts in Russland

Janis Kluge, Berlin

AUS RUSSISCHEN BLOGS

„Nacht der langen Baggerschaufeln«.

Zur Debatte über den Abriss von Kiosken in Moskau

- NOTIZEN AUS MOSKAU

Nach Putin

Jens Siegert, Moskau

UMFRAGE

Demokratie in Russland

Die wirtschaftliche Lage im Januar 2016

Die dringendsten Probleme

Werte und Wertewandel

24

Staatsduma und Präsident: "Die Sonntagsfrage»

\section{CHRONIK}

5. - 18. Februar 2016 


\title{
Gefangen in Informalität
}

\section{Kleine und mittlere Unternehmen im russischen Kapitalismus}

\author{
Alexandra Vasileva, Amsterdam
}

\section{Zusammenfassung:}

Trotz staatlicher Übergriffe auf Privateigentum haben in Putins Russland die kleinen Unternehmen nicht an Bedeutung als Wirtschaftsakteure verloren. Sie begegnen den Bedrohungen durch den Staat mit zwei sich gegenseitig ausschließenden Strategien, einer formalen und einer informellen. Diejenigen Unternehmen, die die informelle Strategie verfolgen, befinden sich in einer rechtlichen Grauzone. Das Damoklesschwert potentieller staatlicher Sanktionen treibt sie dazu, eventuell auftauchende Probleme mit den Behörden weiterhin informell zu lösen. Dadurch geraten die Unternehmer in die Informalitätsfalle und werden Geisel des auf unsicheren Eigentumsrechten basierenden Teufelskreises.

\section{Kleinunternehmer unter den Bedingungen unsicherer Eigentumsrechte}

Unsichere Eigentumsrechte sind eines der "Markenzeichen« der russischen politischen Ökonomie (Grafik 1). Unter Präsident Putin haben insbesondere die staatlichen Übergriffe auf Privateigentum zugenommen, zum Beispiel mittels Erpressung durch die Bürokratie, mit juristischen Schikanen und sogar durch "rejderstwo" (räuberisch feindliche Übernahme von Unternehmen mit Hilfe von Polizei und Justiz). Sowohl große Konzerne als auch kleinere Firmen sind von solchen Übergriffen betroffen. Vor wenigen Tagen erst wurden im Moskauer Zentrum in einer Nacht-und-Nebel-Aktion um die hundert Kioske abgerissen. Die Gebäude wurden in Rückgriff auf ein kürzlich erlassenes Gesetz als "eigenmächtig " gebaut eingestuft und mussten ohne Vorwarnung den staatlichen Bulldozern weichen. Dutzende Eigentümer haben ihren Besitz und Hunderte Mitarbeiter ihre Jobs verloren.

In diesem Kontext mag überraschen, dass die Anzahl kleiner und mittlerer Unternehmen (im Folgenden „KMU«) im letzten Jahrzehnt kontinuierlich gestiegen ist und ihr Anteil an der Beschäftigung zugenommen hat (siehe Grafiken 2 und 3). Freilich können verschiedene Faktoren für diesen positiven Entwicklungstrend verantwortlich sein, die hier allerdings nicht alle näher benannt werde können. In der Tat ist der Anteil der KMU an der Wirtschaft insgesamt gering (zirka 20\% des Bruttoinlandsprodukts und $25 \%$ der Beschäftigten, verglichen mit jeweils über $50 \%$ in westlichen Marktwirtschaften), so dass das Wachstum im Zuge des Wirtschaftsbooms der 2000er Jahre, das von einem sehr niedrigen Niveau ausging, nicht überrascht. Insgesamt lässt sich aber aus dem Wachstumstrend der KMU schließen, dass die Firmen sich an das ungünstige Geschäftsklima angepasst haben.

Welche Strategien haben kleine und mittlere Unternehmen entwickelt, um den Bedrohungen durch den
Staat zu begegnen? Dazu habe ich im Frühjahr 2014 insgesamt 23 kleine russische Unternehmen zu ihren Geschäftsmodellen und zum Umgang mit Behörden befragt, sowie elf Experten interviewt, darunter Leiter von Wirtschaftsverbänden, Juristen, Wirtschaftsjournalisten und Wissenschaftler.

\section{Zwei Strategien der Unternehmen und zwei Gesichter des Staates}

In Russland werden oft zwei Hauptformen wirtschaftlicher Tätigkeit unterschieden, "weiß« und "grau» (die dritte, seit dem Ende der 1990er Jahren seltener werdende Form "schwarz" bezieht sich auf Akteure, die gänzlich in der Schattenwirtschaft agieren). „Weiße« Firmen führen ihr Geschäft grundsätzlich im Einklang mit dem Gesetz und greifen bei Konflikten mit den Behörden zu juristischen Mitteln (zum Beispiel Gerichtsverfahren). „Weiße« Firmen verhalten sich größtenteils konform. "Graue« Firmen hingegen machen von diversen Schattenpraktiken Gebrauch: Sie hinterziehen Steuern oder greifen bei Problemen mit den Behörden auf korrupte "Lösungswege« zurück. "Graue« Firmen verfolgen meist informelle Strategien.

Dieser Dichotomie der Firmenstrategien steht eine gewisse Zwiespältigkeit des russischen Staates gegenüber. Dieser stellt einerseits eine formale Institution dar, die zumindest theoretisch unparteiisch und im Interesse des Allgemeinwohls agiert. Andererseits besteht er aus einer Anhäufung einzelner Bürokraten, die nicht selten Partikularinteressen verfolgen und sich formaler Gewaltinstrumente des Staates als Mittel zum Zweck der eigenen Bereicherung bedienen.

Während der Staat sich sowohl der formalen als auch der informellen Machtinstrumente bedienen kann, schließen sich für Unternehmen die formale und die informelle Strategie in der Praxis oft gegenseitig aus. Wie weiter unten erläutert wird, geraten KMU dadurch oft in eine "Informalitätsfalle«, in einen Teufelskreis des 
informellen Verhaltens, das die Unsicherheit der Eigentumsrechte noch weiter verschärft.

\section{"Formale Strategie« im Umgang mit Behörden}

Die formale Verhaltensstrategie ist der sicherste Weg, Unannehmlichkeiten mit den Behörden zu minimieren, auch wenn sie keine Garantie gegen staatliche Willkür darstellt (Interview: Jurist L2). Vor allem größere Firmen verhalten sich gegenüber den Behörden "konform", da sie sich professionelle Buchhalter und Juristen leisten können. Firmen mit hoher Profitabilität, zum Beispiel in der Pharma-Branche, oder Unternehmen, die keiner starken Konkurrenz ausgesetzt sind, zum Beispiel Hersteller von einzigartigen Produkten oder beliebten Marken, können es sich ebenfalls leisten, im Rahmen des Gesetzes zu agieren. Auch die Branche spielt eine Rolle: Firmen im Dienstleistungssektor haben typischerweise weniger Kontakt mit den kontrollierenden Behörden und sind daher weniger Korruptionssituationen ausgesetzt. Außerdem können solche Firmen korrupte Aktivitäten »outsourcen«: So engagieren beispielsweise Handelsfirmen professionelle »Berater«, die die zu importierende Ware durch den notorisch korrupten Zoll bringen (Interview: Unternehmer B3). Ein anderes Beispiel sind PR-, IT- oder andere Dienstleistungsfirmen, die ihre Büroflächen mieten, sodass sie sich nicht als Eigentümer mit den Kontrollbehörden, zum Beispiel mit der berüchtigten Brandschutzbehörde, auseinandersetzen müssen. Alle Probleme regelt der Vermieter (Interview: Unternehmer B5).

\section{»Informelle Strategie« im Umgang mit Behörden}

Viele kleinere Firmen sowie Firmen im verarbeitenden Gewerbe und in der Gastronomie verfolgen oftmals informelle Strategien im Umgang mit den Behörden und wirtschaften somit in der Grauzone der Legalität. Dabei ist die Steuerhinterziehung die am weitesten verbreitete informelle Praxis. Die informelle Verhaltensstrategie hat mehrere Ursachen, die nicht alle dem direkten staatlichen Druck entspringen.

Ein Grund liegt in den Besonderheiten des rechtlichen und regulatorischen Rahmens unternehmerischer Tätigkeit zusammen. So treiben die unübersehbare Fülle und die gelegentlichen Widersprüchlichkeiten in den Regelungen des Wirtschaftsrechts viele Unternehmer in die Grauzone. Ein Einzelhändler beschreibt das System staatlicher Auktionen, auf denen Gewerbeflächen (Kioske) versteigert werden: „Es wird eine Situation erzeugt, in der es unmöglich ist, alles dem Gesetz entsprechend zu machen. Zum Beispiel wurden sieben $\mathrm{m}^{2}$ für einen Fischkiosk ausgeschrieben. Es ist nicht ein- mal möglich, [auf dieser Fläche] einen Kühlschrank aufzustellen. Oder eine Apotheke mit $10 \mathrm{~m}^{2}$. Laut den Verordnungen muss es dort einen Wasseranschluss geben. [...] Er [Beamter der Gewerbeaufsicht] kommt und sagt: Warum haben Sie kein Wasser?.. Das ist eine Ordnungswidrigkeit. Sie können dir den Laden dichtmachen." (Interview: Unternehmer B19). Der Unternehmer ist in der Zwickmühle: Soll er bewusst den Regelbruch und die formale Strafe in Kauf nehmen oder eine informellemeist billigere - "Lösung" mit dem Beamten finden?

Manchmal erscheint die zweite Option als das geringere Übel, da die russische Wirtschaftsgesetzgebung tendenziell repressiv ist und zudem durch die Beamten willkürlich angewendet werden kann. Ein ehemals inhaftierter Unternehmer kommentiert den Paragraphen 159 des Strafgesetzbuchs (»Betrug»), der eine Haftstrafe von bis zu fünf Jahren für Unternehmer vorsieht: "Das Strafgesetzbuch trägt den sowjetischen Geist des Verbots von Unternehmertum. [...] Insbesondere die Gewinngenerierung wird oft als [illegitimer] Eigennutz interpretiert. [...] Du hast für 100 Rubel statt 90 verkauft - das heißt, 10 hast du gestohlen. Und wo ist das Motiv? Außer dass es das Motiv eines jeden Unternehmers ist, Gewinn zu erwirtschaften?« (Interview: Unternehmer B10).

Die Ausweitung des Kompetenzbereichs der Strafverfolgungsbehörden auf Steuerstraftaten seit Ende 2014 hat den Druck auf die Unternehmer erhöht. Die Androhung eines Strafverfahrens wurde zum wirksamen Druckmittel gegen Unternehmer, da ein Strafverfahren mit der sofortigen Suspendierung der wirtschaftlichen Tätigkeit einhergeht. So werden zum Beispiel häufig Geschäftskonten eingefroren. Als Indikator für die Ausübung von Druck zum Zwecke der persönlichen Bereicherung der Strafverfolgungsbeamten dient die Tatsache, dass der Großteil der Wirtschaftsstrafverfahren (bis zu $80 \%)$ nicht ans Gericht übergeben, sondern nach einer gewissen Zeit eingestellt wird.

Die Erpressung durch Staatsbeamte dient als eine weitere Ursache des informellen Verhaltens der KMU. Oft ist die Erpressung unmittelbar und unverhohlen. So berichtet ein Unternehmer über einen Kollegen, der zwar ein "weißes" Unternehmen führte, aber trotzdem der Steuerbehörde negativ aufgefallen war: „Er hatte sehr große Umsätze aber relativ kleine Gewinne. [...] Bei solchen Umsätzen warf sein Unternehmen wenig Steuern ab. Es wurde angenommen, dass die Gewinnspanne im Allgemeinen höher sei, als bei ihm. Das heißt, er hinterzieht, der Mistkerl! [...] Sie [die Steuerbeamten] kommen an und eine Beamtin verkündet sofort: Wir werden Ihnen gleich die hinterzogenen Steuern in Rechnung stellen. [...] Sie wissen doch bestens, dass wir fündig werden. Also, um Ihre und unsere Zeit nicht zu 
verschwenden - wir haben in Bezug auf Sie einen Plan [eine Vorgabe], über drei Millionen. [Legen Sie] hier einhundert [Tausend in bar auf den Tisch], dann werden es zwei Millionen, und wir verabschieden uns«. Sie sind zu ihm gegangen, wie auf Arbeit, zwei Monate lang. Zum Schluss fingen sie an zu winseln, da es wirklich nichts [zu beanstanden] gab. Sie haben etwa 200.000 Rubel gefunden. Kleine [Buchhaltungs] Fehler. Aber sie haben einen Plan: drei Millionen. Sie beschwerten sich, sagten offen: `Bringen Sie uns nicht um! Denn falls sie nach einer zweimonatigen Kontrolle leer zurückkehren, werden sie einfach gefeuert. [...] Sie haben sich geeinigt, dass er die 300.000 statt drei Millionen berechnet bekommt, und die Weiber sind abgehauen, und es ist nicht ausgeschlossen, dass sie gefeuert wurden. Er war gezwungen, einzuwilligen, obwohl er diese Zusatzsteuern vor Gericht hätte anfechten können. Er hat eingewilligt, damit sie einfach verschwinden und ihn nicht bei der Arbeit stören." (Interview: Unternehmer B3).

Diese Situation verdeutlicht die »beschuldigende» Haltung des Staates zum Unternehmertum. Gewinnerzielung wird als Spekulation gebrandmarkt; ein zu kleiner Gewinn hingegen wird als Betrug an der Staatskasse interpretiert: "Das System erkennt in jedem Unternehmer nach wie vor einen Gegner, der a priori Steuern hinterzieht" (Interview: Unternehmer B20). Sogar ein "weißer« Unternehmer entscheidet sich aus pragmatischen Gründen für eine informelle Strategie und begibt sich somit in die Grauzone, was ihn dann für weitere bürokratische Schikanen angreifbar macht.

Manchmal nimmt die bürokratische Erpressung subtile Formen an. So berichten einige Unternehmer, dass Steuerbehörden ungern Verluste hinnehmen, da diese die Steuerstatistik verderben: "Wenn deine Verluste steigen, lädt sie [die Steuerbehörde] dich vor und fängt an dich zu erziehen: 'So nicht! Zeig [den Verlust] lieber nicht, nicht in der Steuererklärung, wir werden uns schon einigen. Einerseits will ich mich absichern, um mit keinen weiteren Forderungen konfrontiert werden zu müssen, aber andererseits gebe ich nach und gehe einen Kompromiss ein. Und dann können sie mich mit diesem Kompromiss jederzeit am Kragen packen.» (Interview: Unternehmer B16).

Eine weitere verdeckte Form der Erpressung geschieht durch Firmen, die mit bestimmten Beamten »assoziiert« sind. In einigen Regionen ist der Markt quasifeudal in informelle Einflusszonen aufgeteilt, die jeweils von bestimmten Bürokraten oder befreundeten Unternehmern »betreut" werden. Diese indirekte Übernahme von Teilen der Wirtschaft durch staatliche Funktionsträger erschwert den Marktzugang für neue KMU. Laut einer "Outsider"-Firma, die in einer sibirischen Region ein Hotel bauen wollte, lud der Bürger- meister zur Vorbesprechung des Projektes ein Team von "Banditen« mit ein: "Gebt uns euer Projekt, wir werden alles bauen. Gebt euer Geld her, das Bauunternehmen stellen wir, die Baustoffe ebenfalls, sonst arbeitet niemand hier. Wir haben eine Firma für die ganze Region, die alles baut. Schluss. Wenn ihr versuchen wollt, etwas ohne uns zu bauen, wird euch nichts gelingen." (Interview: Unternehmer B10).

Schließlich dient die vorherrschende Normalität der Informalität als Ursache des informellen Verhaltens von KMU. Die Informalität hat eine lange historische Tradition in Russland: Man denke zum Beispiel an die informellen Überlebensstrategien gegenüber dem autoritären Staat aus wirtschaftlicher Not, man denke an das traditionelle Vertrauen auf eigene private Netzwerke angesichts eines Fehlens funktionierender unparteiischer Institutionen oder an Bestechung und andere Formen der Korruption.

Ein Aspekt dieser Normalität der Informalität bezieht sich auf die verbreitete Vorstellung, dass die gesamte russische Geschäftswelt auf Schattenpraktiken zurückgreife, und dass es unmöglich sei, ohne diese Praktiken gewinnbringend zu wirtschaften. Vor allem Steuerhinterziehung wird als ein Wettbewerbsfaktor angesehen: »Ich will kein Steuersünder sein, kein Damoklesschwert über mir hängen haben. Was passiert in diesem Fall? Dann bin ich sofort nicht mehr wettbewerbsfähig, da das [die Steuerhinterziehung] die Regel ist, der der gesamte Markt folgt. Du wirst preistechnisch nicht mehr wettbewerbsfähig sein. Du wirst Steuern bezahlen, die um ein Mehrfaches höher sind als die, die alle anderen zahlen." (Interview: Unternehmer B20). Informelle Partikularstrategien unterminieren die universellen Regeln und treiben die Firmen in die Schattenwirtschaft. Dies erinnert an den Anpassungsmechanismus der russischen Gesellschaft als Ganzes, den der Soziologe Alexej Lewinson 2008 in einem Interview beschreibt: "Das individuelle Freikaufen vom Staat hat die Keime des Universalismus in unserer Gesellschaft vernichtet" (<http://www.novayagazeta.ru/poli tics/40804.html $>$ ).

Ein anderer Aspekt dieser Normalität der Informalität bezieht sich auf die ebenfalls verbreitete Vorstellung vom Staat als einem korrupten, willkürlichen und das Individuum unterdrückenden Gebilde. Demzufolge sei es fast eine Tugend, den Staat zu betrügen. Einige Unternehmer zahlen nur einen Teil der Steuern - "gemäß unserer Möglichkeiten« - oder bedauern es, überhaupt Steuern zu zahlen, weil sie sich nicht sicher sind, ob das Geld in der Staatskasse ankommt (Interview: Unternehmer B12).

Gleichzeitig werden informelle Netzwerke mit den einzelnen Dienern des Staates als äußerst nützlich und 
geradezu selbstverständlich angesehen, als "PatronSchützling-Beziehungen" wie im alten Rom» (Interview: Unternehmer B20). Die zwei wichtigsten Funktionen dieser informellen Netzwerke sind das Vorbeugen von Problemen mit den Behörden sowie die Lösung auftretender Probleme. Zum Beispiel stellte der Eigentümer einer kleinen Klinik den Sohn des städtischen Amtsarztes ein, "also den Sohn des Beamten, der mich zu kontrollieren hat, damit keine künstlich erzeugten Probleme entstehen « (Interview: Unternehmer B6). Der Betreiber einer Kette mobiler Wurstkioske hingegen löste die verschiedenen Probleme mit der lokalen Polizei sogar mehrmals im Laufe des Interviews, indem er seine hochrangigen Beschützer im Polizeiapparat anrief und um Hilfe bat (Interview: Unternehmer B13).

Schließlich führt die herrschende Normalität der Informalität zur selbstverständlichen Akzeptanz eines Geschäftsmodells, das auf mündlichen Absprachen basiert und somit zumindest teilweise am Fiskus vorbeigeht. So berichtet der Geschäftsführer eines kleinen Übersetzungsbüros, dass "wir viele Kunden haben, die gar keine Zahlungsbelege benötigen. [...] Wir arbeiten mit fünf großen Stammkunden. Ich kenne sie persönlich [aus dem Studium]. [...] Bei uns in Russland wird doch alles über Bekanntschaften geregelt." (Interview: Unternehmer B9). Andere "Steuersparmaßnahmen« werden ebenfalls als Effizienzfaktor angesehen, wie ein junger Gastronom berichtet, der laut eigener Aussage Korruption nicht für bedenklich hält: »Man soll das Minimum erfüllen, das die Gesetzgebung vorgibt. Einerseits soll man nicht offensichtlich gegen etwas verstoßen; andererseits: Alles darüber hinaus ist weniger effektiv... Vermutlich ist das die effektivste Methode, um Geld zu verdienen, nämlich an der unteren Grenze dessen zu bleiben, was man unbedingt machen muss [was gesetzlich gefordert ist].» (Interview: Unternehmer B5).

\section{Informalitätsfalle}

Die beschriebene Vielfalt der Gründe macht deutlich, dass nur ein Teil des informellen Verhaltens der kleinen Firmen als Anpassungsreaktion auf staatlichen Druck $\mathrm{zu}$ verstehen ist. In vielen Situationen verhalten sich die Unternehmer informell, weil sie höhere Gewinne anstreben oder versuchen, ihre Konkurrenten auszustechen. So erscheinen KMU nicht nur als passive Opfer der staatlichen Willkür, sondern als aktive Mitgestalter des durchgängig korrupten Systems.

Unabhängig von ihren konkreten Ursachen, ist es jedoch wichtig festzuhalten, dass die Informalität einen Teufelskreis impliziert: Firmen, die informell agieren, geraten oft in die "Informalitätsfalle« und werden dauerhaft in die Schattenwirtschaft gedrängt. Der Mechanismus dieser Falle ist folgender: Während der Staat potentiell zwei Druckmittel gegen die Unternehmer besitzt, einerseits die formalen Gesetze und andererseits ihre Instrumentalisierung zum privaten Nutzen durch die Bürokraten, können sich die Firmen nur durch eine der sich gegenseitig ausschließenden Strategie verteidigen. Entweder gehen sie den legalen Weg oder sie handeln mithilfe von Beziehungen und korrupten Kanälen. Warum aber haben die Firmen im Gegensatz zum Staat keine Möglichkeit, sich gleichzeitig sowohl im formalen als auch im informellen Feld zu bewegen?

"Weiße« Firmen haben per se wenig Spielraum für informelle Praktiken. So haben sie zum Beispiel kein Schwarzgeld, das meist mithilfe von Briefkastenfirmen generiert wird. Andererseits haben "graue« Unternehmen im Falle eines Konflikts mit dem Staat ebenfalls praktische Schwierigkeiten, sich formaler Mittel zu bedienen. So ist der Rechtsweg für viele "graue« Firmen, die tendenziell kleine und ressourcenarme Firmen sind, kostspielig und zeitintensiv. Auch ist es für eine Firma problematisch, vor Gericht zu ziehen, wenn sie selbst gegen Gesetze verstoßen hat (zum Beispiel Schwarzgeld eingesetzt hat), da der Verstoß ans Licht kommen könnte (die Briefkastenfirma kann aufgedeckt werden). Manche "graue" Unternehmer versuchen trotzdem den Rechtsweg, teilweise mit fragwürdigem Erfolg. So hat ein Moskauer Mobiltelefonhändler das Gerichtsverfahren gegen die Steuerbehörde gewonnen, die ihn der Steuerhinterziehung verdächtigt hatte, obwohl er in der Tat schuldig war. Nach dem Vorfall haben die Beamten der Steuerbehörde jedoch informell angedeutet, dass die Firma nun »unter die Lupe genommen wird« (Interview: Unternehmer B18).

Die Rache der Behörden ist grundsätzlich einer der Gründe, weshalb es vielen Unternehmern »nicht in den Sinn kommt, sich zu wehren « (Interview: Unternehmer B10). Einer der Geschäftsführer des Kleinunternehmerverbandes OPORA kommentiert: "Wenn ein Unternehmer sich über einen Bürokraten beschwert, über seine korrupten Handlungen, bringt er sowohl sich selbst als auch seine Geschäft in große Gefahr. Denn niemand kann verhindern, dass die staatlichen Organe sich an ihm rächen. Sich [offiziell] zu beschweren ist schlichtweg gefährlich." (Interview: Wirtschaftsverbandsleiter A2).

Ähnlich verhält es sich mit Unternehmen, deren Geschäftsmodell von Staatsaufträgen abhängig ist. Beispielsweise berichten kleine Baufirmen, dass offizielle Beschwerden, zum Beispiel wegen einer Verzögerung oder gar des Ausbleibens der Bezahlung, dazu führen, dass die Firma auf eine inoffizielle "schwarze Liste" gesetzt wird und künftig keine Aufträge mehr bekommt (Interview: Unternehmer B18). Hinzu kommt, dass das staatliche Auftragswesen von Korruption durchsetzt ist, vor allem in Form von Kickbacks, was zur Veruntreu- 
ung von Haushaltsgeldern führt. Firmen, die wohl oder übel Kickbacks bezahlen, sind auf die Generierung von Schwarzgeld angewiesen, und sie begeben sich dadurch automatisch in die Schattenwirtschaft. Dies verringert die Möglichkeiten, ihre Rechte auf formalem Weg zu verteidigen.

In jedem Fall hängt über Firmen, die formale Regeln umgehen und sich der informellen Strategie im Umgang mit den Behörden bedienen, das Damoklesschwert potentieller staatlicher Sanktionen bis hin zur Strafverfolgung. Im Ergebnis müssen die Unternehmer eventuell auftauchende Probleme weiterhin meist informell lösen, denn wenn »alles auf Beziehungen basiert, gibt es keine Basis für Rechtssicherheit" (Interview: Unternehmer B22). Partikulare Absprachen schließen einheitliche Spielregeln aus und liefern "einen fruchtbaren Boden für die Generierung von Schattenerträgen auf allen Ebenen" (Interview: Unternehmer B20). Die Unternehmer geraten in die Informalitätsfalle und werden Geisel eines korrumpierten Systems. Der Teufelskreis der Informalität schließt sich.

\section{Ausblick}

Die gegenwärtige wirtschaftliche Krise in Russland angesichts des Ölpreisverfalls und der westlichen Sank- tionen verschärft die ohnehin prekäre Situation der kleinen und mittleren Unternehmen. Die wachsende staatliche Bedrängung der KMU, wie das aktuelle Beispiel des massenhaften Abrisses Moskauer Kioske zeigt, könnte eine sich verschärfende bürokratische Konkurrenz um die schwindenden Ressourcen bedeuten. Dabei gefährdet dieses räuberische staatliche Vorgehen nicht nur die Eigentumsrechte, sondern schränkt auch die Beschäftigungsmöglichkeiten für viele Menschen ein und treibt sie potentiell in die Schattenwirtschaft. Dennoch könnte das Kioskbeispiel aus der Perspektive der Informalitätsfalle gedeutet werden. Wie der oppositionelle Aktivist Alexej Nawalnyj in seinem Blog argumentiert, waren die Kioskbesitzer zwar formal die legalen Eigentümer, haben aber oftmals die nötigen Baugenehmigungen nicht rechtmäßig erhalten, möglicherweise durch informelle oder gar korrupte Kanäle. Die Behörden könnten die Papiere deshalb jederzeit für ungültig und das Eigentum für nichtig erklären.

\section{Über die Autorin}

Alexandra Vasileva ist Doktorandin an der Universität Amsterdam in der Forschungsgruppe »Politische Ökonomie«. In ihrer Promotion untersucht sie Kontinuität, Wandel und Machtbeziehungen im russischen Kapitalismus seit dem Zerfall der Sowjetunion.

\section{Lesetipps}

- Gans-Morse, J.: Threats to Property Rights in Russia: From Private Coercion to State Aggression, in: Post-Soviet Affairs, (28) 2012, Nr. 3, S. 263-295.

- Gessen, M.: Moscow Just Razed Its Small Businesses and Became Even Blander, in: The New Yorker, 10. Februar 2016; $<$ http://www.newyorker.com/news/news-desk/moscow-just-razed-its-small-businesses-and-became-even-blander >.

- Yakovlev, A., A. Sobolev, A. Kazun: Means of Production Versus Means of Coercion: Can Russian Business Limit the Violence of a Predatory State?, in: Post-Soviet Affairs, (30) 2014, Nr. 2-3, S. 171-194. 


\section{Tabelle 1: Liste der Interviewpartner}

Unternehmer $=$ Besitzer eines kleinen $(/ \mathrm{K})$ oder mittleren $(/ \mathrm{M})$ Unternehmens.

* = Direktor. Kleines Unternehmen: 1-50 Mitarbeiter; mittleres Unternehmen: 51-100 Mitarbeiter

\begin{tabular}{|c|c|c|c|}
\hline Position & Code & Geschäftsform & $\begin{array}{l}\text { Datum des } \\
\text { Interviews }\end{array}$ \\
\hline Unternehmer/M, Nähfabrik, Moskauer Gebiet & B1 & Weiß? & 4.04 .2014 \\
\hline Unternehmer/K, Verlagshaus, Moskau & $\mathrm{B} 2$ & Weiß & 4.04 .2014 \\
\hline Unternehmer/K, Einzelhandel, Moskau & B3 & Weiß? & 6.04 .2014 \\
\hline Unternehmer/K, PR-Agentur, Moskau & B4 & Weiß & 8.04 .2014 \\
\hline Unternehmer/K, Gastronomie, Moskau & B5 & Grau & 8.04 .2014 \\
\hline Unternehmer/K, Klinik, Moskau & B6 & Grau & 9.04 .2014 \\
\hline Unternehmer/K, Bau, Moskau & B7 & Grau & 10.04 .2014 \\
\hline Unternehmer/S, Kindergarten, Moskau & B8 & Weiß? & 10.04 .2014 \\
\hline $\begin{array}{l}\text { Unternehmer/K, Anwaltskanzlei und Übersetzungsbüro, } \\
\text { Moskau }\end{array}$ & B9 & Grau & 10.04 .2014 \\
\hline $\begin{array}{l}\text { Unternehmer/M*, verarbeitendes Gewerbe (Chemie), } \\
\text { Moskau }\end{array}$ & $\mathrm{B} 10$ & Weiß & 11.04 .2014 \\
\hline Unternehmer/K, Übersetzungsbüro, Moskau & B11 & Grau & 11.04 .2014 \\
\hline Unternehmer/K, Bau, Moskau & $\mathrm{B} 12$ & Grau & 14.04 .2014 \\
\hline Unternehmer/K, Einzelhandel, Moskau & B13 & Grau? & 15.04 .2014 \\
\hline $\begin{array}{l}\text { Unternehmer/M, verarbeitendes Gewerbe (Metall), } \\
\text { Wyschnij Wolotschek (Gebiet Twer) }\end{array}$ & B14 & Grau & 15.04 .2014 \\
\hline Unternehmer/M, IT, Moskau & B15 & Weiß? & 15.04 .2014 \\
\hline $\begin{array}{l}\text { Unternehmer/M, verarbeitendes Gewerbe (Möbel), } \\
\text { Kaluga (Gebiet Kaluga) }\end{array}$ & $\mathrm{B} 16$ & Weiß? & 16.04 .2014 \\
\hline $\begin{array}{l}\text { Unternehmer/M*, verarbeitendes Gewerbe (Plastik), } \\
\text { St. Petersburg }\end{array}$ & $\mathrm{B} 17$ & Weiß? & 17.04 .2014 \\
\hline $\begin{array}{l}\text { Unternehmer/M verarbeitendes Gewerbe (Metall), } \\
\text { St. Petersburg }\end{array}$ & $\mathrm{B} 18$ & Grau? & 17.04.2014 \\
\hline Unternehmer/K, Einzelhandel, Moskau & B19 & Grau? & 18.04 .2014 \\
\hline Unternehmer/M, Einzelhandel, Moskau & $\mathrm{B} 20$ & Grau & 21.04 .2014 \\
\hline $\begin{array}{l}\text { Unternehmer/M, verarbeitendes Gewerbe } \\
\text { (Konditoreiwaren), Moskau }\end{array}$ & $\mathrm{B} 21$ & Grau & 21.04 .2014 \\
\hline $\begin{array}{l}\text { Unternehmer/S, verarbeitendes Gewerbe } \\
\text { (Industrieventilatoren), Selenograd (Moskauer Gebiet) }\end{array}$ & $\mathrm{B} 22$ & Grau & 22.04.2014 \\
\hline Unternehmer/K, Autohandel, Moskau & $\mathrm{B} 23$ & Grau & 23.04 .2014 \\
\hline Leiter eines Wirtschaftsverbandes, Moskau & A1 & & 3.04 .2014 \\
\hline Leiter eines Wirtschaftsverbandes, Moskau & A2 & & 7.04.2014 \\
\hline Leiter eines Wirtschaftsverbandes, Moskau & A3 & & 8.04 .2014 \\
\hline $\begin{array}{l}\text { Jurist (Zentrum »Unternehmer gegen Korruption»), } \\
\text { Moskau }\end{array}$ & L1 & & 7.04 .2014 \\
\hline Jurist, private Anwaltskanzlei, Moskau & $\mathrm{L} 2$ & & 7.04.2014 \\
\hline Wissenschaftler, Moskau & E1 & & 9.04 .2014 \\
\hline Wissenschaftler, Moskau & E2 & & 14.04 .2014 \\
\hline Wissenschaftler, Moskau & E3 & & 21.04 .2014 \\
\hline Wissenschaftler, Moskau & E4 & & 22.04 .2014 \\
\hline Journalist, »Kommersant Dengi«, Moskau & J1 & & 8.04 .2014 \\
\hline Journalist, »Forbes Russia«, Moskau & $\mathrm{J} 2$ & & 11.04 .2014 \\
\hline
\end{tabular}


Grafik 1: Freiheit der Eigentumsrechte

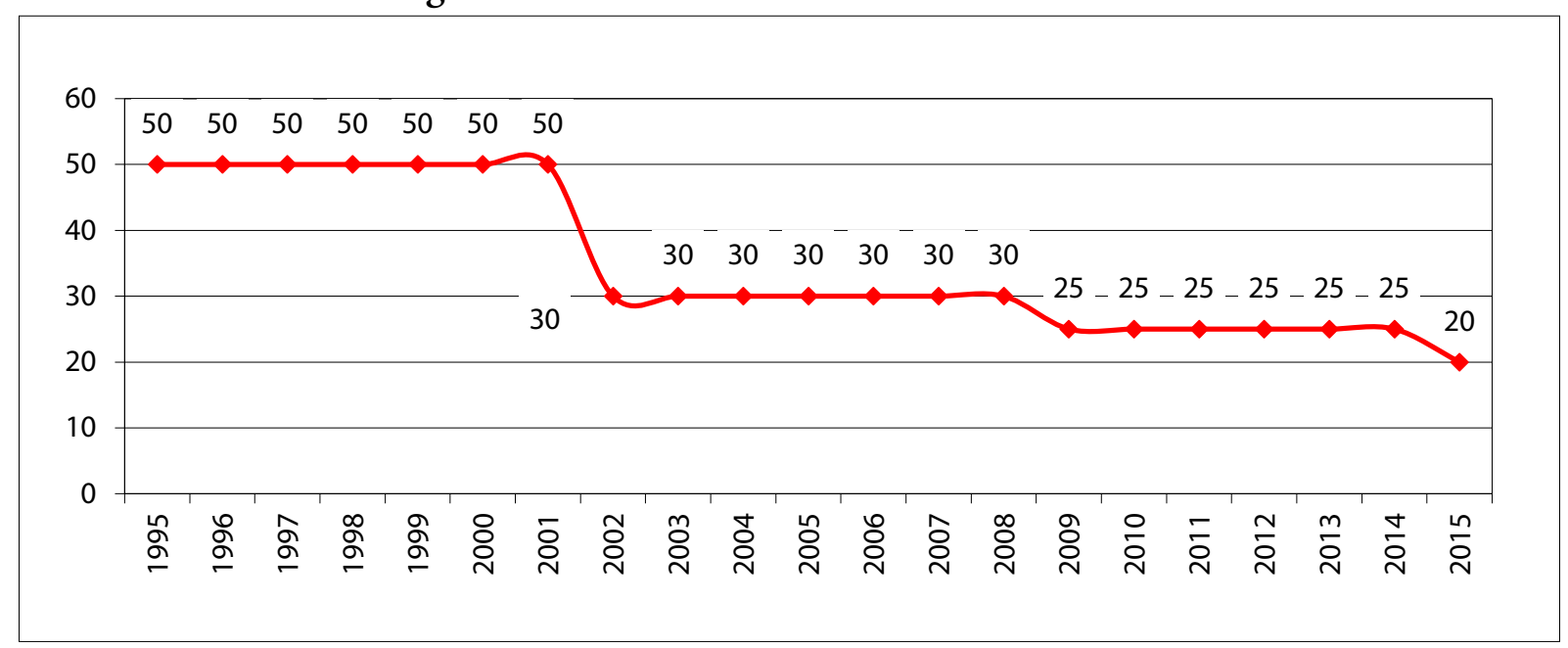

$0=$ nicht frei, $100=$ frei

Quelle: Heritage Foundation, Index of Economic Freedom. Indikator "property rights". <http://www.heritage.org/index/ visualize?cnts=russia\&type $=8>$

Grafik 2: Anzahl der kleinen Firmen (1991-2013)

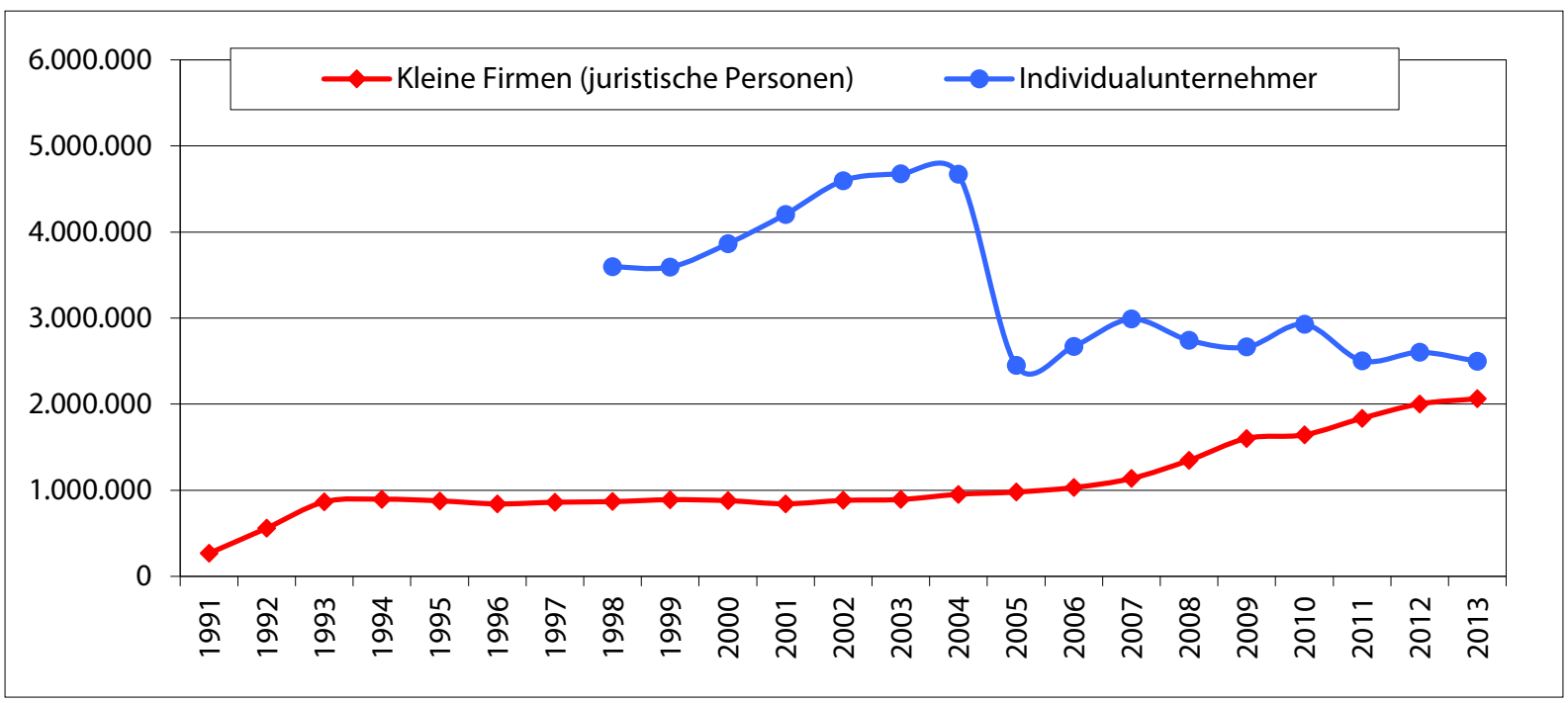

Quelle: Rosstat (diverse Jahre). "Maloje i srednee predprinimatelstwo Rossii«. <http://www.gks.ru/wps/wcm/connect/rosstat_main/ rosstat/ru/statistics/publications/catalog/doc_1139841601359>

Tabelle 2: Anzahl der kleinen Firmen (1991-2013)

\begin{tabular}{|l|c|c|}
\hline & Kleine Firmen (juristische Personen) & Individualunternehmer \\
1991 & 268.000 & \\
1992 & 560.000 & \\
1993 & 865.000 & \\
1994 & 896.000 & \\
\hline
\end{tabular}


Tabelle 2: Anzahl der kleinen Firmen (1991-2013) (Forsetzung)

\begin{tabular}{|l|c|c|}
\hline & Kleine Firmen (juristische Personen) & Individualunternehmer \\
1995 & 877.300 & \\
1996 & 841.700 & \\
1997 & 861.100 & 3.599 .000 \\
1999 & 868.000 & 3.592 .900 \\
2000 & 890.600 & 3.865 .000 \\
2001 & 879.300 & 4.205 .900 \\
2002 & 843.000 & 4.596 .300 \\
2003 & 882.300 & 4.675 .000 \\
2004 & 893.000 & 4.670 .100 \\
2005 & 953.100 & 2.448 .900 \\
2006 & 979.300 & 2.672 .400 \\
2007 & 1.032 .000 & 2.988 .300 \\
2008 & 1.137 .000 & 2.742 .000 \\
2009 & 1.347 .667 & 2.663 .900 \\
2010 & 1.602 .491 & 2.927 .488 \\
2011 & 1.644 .269 & 2.505 .100 \\
2012 & 1.836 .432 & 2.602 .300 \\
2013 & 2.003 .038 & 2.499 .000 \\
\hline
\end{tabular}

Quelle: Rosstat (diverse Jahre). "Maloje i sredneje predprinimatelstwo Rossii«. <http://www.gks.ru/wps/wcm/connect/rosstat_main/ rosstat/ru/statistics/publications/catalog/doc_1139841601359>

\section{Grafik 3: Anteil der KMU an der Beschäftigung}

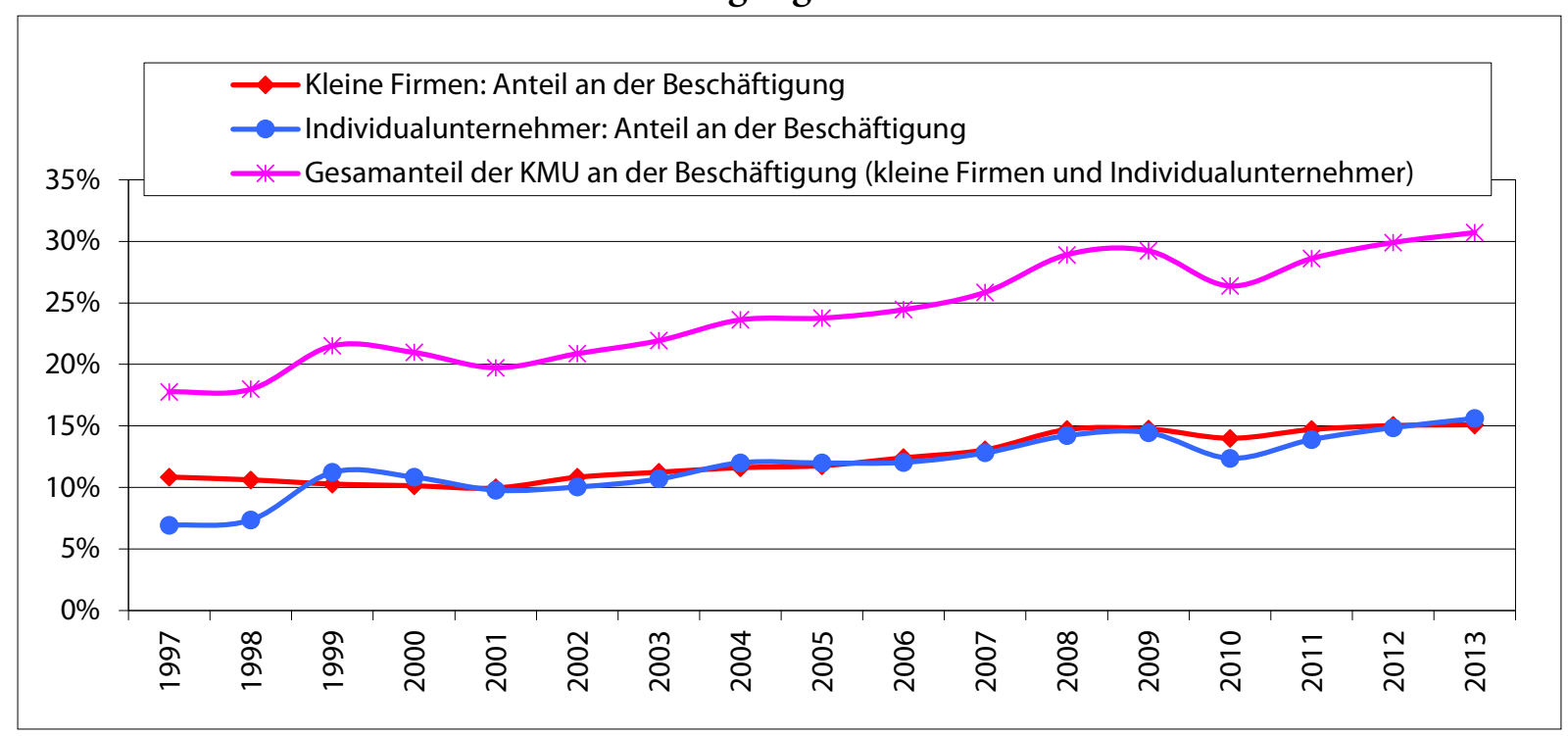

Quelle: Rosstat; siehe Tabelle 3 und 4. 
Tabelle 3: Anteil der KMU an der Beschäftigung

\begin{tabular}{|c|c|c|c|}
\hline & $\begin{array}{c}\text { Anzahl der Beschäftigten in } \\
\text { kleinen Firmen }\end{array}$ & $\begin{array}{c}\text { Anzahl der } \\
\text { Beschäftigten im Sektor } \\
\text { "Individualunternehmertum» }\end{array}$ & $\begin{array}{l}\text { Gesamtzahl der Beschäftigten } \\
\text { in der russischen Wirtschaft }\end{array}$ \\
\hline \multicolumn{4}{|l|}{1991} \\
\hline 1992 & & & 72.071 .000 \\
\hline \multicolumn{4}{|l|}{1993} \\
\hline 1994 & 8.479 .900 & & \\
\hline 1995 & 8.994 .800 & & 66.409 .000 \\
\hline 1996 & 6.269 .100 & & \\
\hline 1997 & 6.514 .800 & 4.151 .000 & 60.021 .000 \\
\hline 1998 & 6.207 .800 & 4.300 .000 & 58.437 .000 \\
\hline 1999 & 6.485 .800 & 7.081 .000 & 63.082 .000 \\
\hline 2000 & 6.596 .800 & 7.051 .000 & 65.070 .400 \\
\hline 2001 & 6.483 .500 & 6.368 .000 & 65.122 .900 \\
\hline 2002 & 7.220 .300 & 6.691 .000 & 66.658 .900 \\
\hline 2003 & 7.458 .900 & 7.092 .000 & 66.339 .400 \\
\hline 2004 & 7.815 .100 & 8.087 .000 & 67.318 .600 \\
\hline 2005 & 8.045 .200 & 8.194 .000 & 68.339 .000 \\
\hline 2006 & 8.582 .800 & 8.331 .000 & 69.168 .700 \\
\hline 2007 & 9.239 .200 & 9.064 .000 & 70.770 .300 \\
\hline 2008 & 10.436 .900 & 10.090 .000 & 71.003 .100 \\
\hline 2009 & 10.247 .500 & 10.040 .000 & 69.410 .500 \\
\hline 2010 & 9.790 .200 & 8.650 .000 & 69.933 .700 \\
\hline 2011 & 10.421 .900 & 9.840 .000 & 70.856 .600 \\
\hline 2012 & 10.755 .700 & 10.633 .000 & 71.545 .400 \\
\hline 2013 & 10.775 .200 & 11.146 .000 & 71.391 .500 \\
\hline
\end{tabular}

Quellen: Rosstat (verschiedene Jahre): "Maloje i sredneje predprinimatelstwo Rossii ", Indikator "Srednespisochnaja tschislennost rabotnikow bes wneschnich sowmestitelej «, <http://www.gks.ru/wps/wcm/connect/rosstat_main/rosstat/ru/statistics/publications/catalog/ doc_1139841601359>; Ekonomitscheskaja Aktiwnost Naselenija Rossii, Indikator "Sanjatije w Ekonomike ", "Raspredelenije tschislennosti sanjatich w ekonomike po mestu osnownoj raboty", <http://www.gks.ru/wps/wcm/connect/rosstat_main/rosstat/ru/statistics/ publications/catalog/doc_1139918584312>. 


\section{Importierte Rechtssicherheit}

\section{Ursachen und Perspektiven der Nutzung ausländischen Rechts in Russland}

Janis Kluge, Berlin

\section{Zusammenfassung:}

Russische Unternehmen nutzen zur Absicherung ihrer Geschäfte untereinander in großem Stil ausländisches Recht und ausländische Gerichte. Das zeigen sowohl die Fallstatistiken ausländischer Handels- und Schiedsgerichte als auch Umfragen unter russischen Firmen. Damit reagiert die Wirtschaft auf die unzureichende Entwicklung des Wirtschaftsrechts und das fehlende Vertrauen in die russischen Wirtschaftsgerichte. Die Nutzung ausländischen Rechts ist eine wesentliche Ursache für die große Zahl an russischen OffshoreHoldings in Zypern und anderen Staaten, die ein Charakteristikum des postsowjetischen Kapitalismus in Russland geworden sind. Eine umfassende Reform des Zivilrechts hat in den letzten Jahren viele formale Gründe für die Nutzung ausländischen Rechts beseitigt. Allerdings ist fraglich, ob dies ausreicht, um die russische Wirtschaft tatsächlich zur Rückkehr in die heimische Jurisdiktion zu bewegen.

\section{Russische Unternehmer vor ausländischen Gerichten}

Das Handelsgericht im modernen "Rolls Building" in London war schon kurz, nachdem es im Dezember 2011 von Königen Elisabeth II. eröffnet wurde, die Bühne eines aufsehenerregenden Gerichtsprozesses zweier russischer Großunternehmer. Der inzwischen verstorbene Boris Beresowskij verklagte seinen Landsmann Roman Abramowitsch mit dem Ziel, einen Milliardenanspruch aus der zehn Jahre zurückliegenden Fusion des Aluminiumkonzerns RusAl geltend zu machen. Über das Verfahren der beiden exzentrischen Oligarchen wurde ausführlich berichtet, dabei sind Prozesse mit russischer Beteiligung in England keine Seltenheit. In den vergangenen fünf Jahren standen jährlich 25-30 russische Kläger und Angeklagte vor dem Londoner Handelsgericht. Nur Engländer und US-Amerikaner waren hier häufiger anzutreffen.

Auch die Statistiken in den wichtigen internationalen Schiedsgerichten zeugen von einer intensiven Nutzung durch russische Unternehmen. Im Schiedsgericht der Stockholmer Handelskammer stellt Russland stets die größte Fraktion unter den nicht-schwedischen Prozessteilnehmern. Auch in der Statistik anderer europäischer Schiedsgerichte, wie dem »London Court of International Arbitration" (LCIA) und dem Schiedsgericht der Internationalen Handelskammer in Paris, landet Russland jedes Jahr auf den vorderen Plätzen.

Diese Zahlen sind ein Hinweis auf die Rolle, die ausländisches Recht und ausländische Gerichte für die russische Wirtschaft spielen. Zwar ist die Zunahme internationaler Gerichts- und Schiedsverfahren ein allgemeiner Trend, der mit der Vertiefung der wirtschaftlichen Integration einhergeht. Allerdings erklärt diese Entwicklung die Zahlen zu Verfahren mit russischer Beteiligung nicht vollständig. Die Nutzung ausländi- scher Gerichte durch russische Unternehmen steht in keinem Verhältnis zum Umfang Russlands außenwirtschaftlicher Beziehungen.

Aufschluss ergab eine Befragung, die 2012 von der Moskauer Anwaltskanzlei »Egorov Puginsky Afanasiev \& Partners" unter mehreren hundert Kanzleikunden durchgeführt wurde. Dabei gab über die Hälfte der befragten Firmen an, das russische Recht für weniger als $10 \%$ ihrer Verträge zu nutzen. Diese Zahl ist besonders erstaunlich, wenn man die Motive für die Nutzung ausländischen Rechts berücksichtigt: Nur 14\% der Unternehmen nannten ausländische Vertragspartner als Grund. Russische Unternehmen bevorzugen ausländisches Recht also auch dann, wenn es sich um innerrussische Geschäfte handelt.

\section{Was spricht gegen russisches Recht?}

Das wichtigste Motiv, einen Vertrag ausländischem Recht zu unterstellen, sind die Mängel des russischen Rechtssystems. Das zeigen die Ergebnisse der Befragung: Einerseits stören die Unternehmen formale Beschränkungen durch russische Gesetze (67\%), andererseits versuchen sie, den russischen Wirtschaftsgerichten aus dem Weg zu gehen (62\%). Dabei geht es um sehr verschiedene Rechtsgeschäfte wie etwa Lieferverträge, Immobiliengeschäfte, Firmenübernahmen oder Lizenzvereinbarungen.

Tatsächlich ist das russische Recht bis vor kurzem im Hinblick auf viele Geschäfte sehr unflexibel gewesen. Besonders reformbedürftig waren das Gesellschaftsrecht und das Vertragsrecht, mit denen Unternehmen ihre Geschäftsbeziehungen und ihre Struktur juristisch fixieren. Das russische Recht kannte lange Zeit viele der moderneren Rechtsinstitute nicht, wie etwa Bedingungen, Garantien oder auch Gesellschaftervereinbarungen.

Auch Zusicherungen waren nicht geregelt: Wollte eine Firma z. B. ein anderes Unternehmen kaufen, 
konnte sie nicht alle Angaben des Verkäufers im Vorhinein prüfen. So kann sich nach einigen Monaten herausstellen, dass das gekaufte Unternehmen bestimmte Technologien einsetzt, ohne die dafür benötigten Lizenzen erworben zu haben. Über eine Zusicherung im Kaufvertrag kann der Verkäufer hierfür im Vorhinein die Haftung übernehmen. Dies war bis vor kurzem nach russischem Recht nicht möglich. Das Fehlen dieser Rechtsmechanismen erschwerte es, Geschäfte im Vorfeld abzusichern und schränkte die Ausgestaltung von Übernahmen, Fusionen und Joint Ventures deutlich ein. Inzwischen sind viele dieser Institute eingeführt worden, allerdings mangelt es bislang an Erfahrungswerten aus der Praxis russischer Gerichte.

Der Wunsch, im Konfliktfall nicht vor ein russisches Wirtschaftsgericht (Arbitrashnyj sud), sondern möglichst vor ein Gericht im europäischen Ausland zu ziehen, hat mehrere Ursachen. Zwar werden die russischen Wirtschaftsgerichte für kleinere und einfachere Verträge viel genutzt. Allerdings gelten Unerfahrenheit von Richtern, politische Beeinflussbarkeit und Korruption als Risikofaktoren, die man bei komplizierten Transaktionen mit hohem Streitwert besser vermeidet. Die bekanntesten Beispiele beeinflusster Gerichtsentscheidungen stammen aus der Abwicklung von Chodorkowskijs YukosKonzern. Neben der Beeinflussbarkeit ist die Neigung zum Formalismus in russischen Wirtschaftsgerichte ein zusätzlicher Unsicherheitsfaktor: Verträge werden häufig für ungültig erklärt, wenn sie nicht exakt in den strikten Rahmen des russischen Rechts passen.

\section{Verträge nach ausländischem Recht in der Praxis}

Grundsätzlich hindert niemand zwei russische Unternehmen daran, untereinander einen Vertrag nach ausländischem Recht zu schließen, in dem für den Konfliktfall ein Gerichtsstand im Ausland gewählt wird. Die wichtigste Alternative zum russischen Recht ist dabei das englische Recht. Dieses ist in der internationalen Geschäftswelt wegen seiner Anpassungsfähigkeit sehr beliebt. Die Wahl des Rechts steht aber auch im Zusammenhang mit dem Gericht, vor dem ein etwaiger Konflikt geschlichtet werden soll. Dabei muss bedacht werden, wie letztlich die Durchsetzung des Gerichtsurteils funktionieren soll.

Eine beliebte Möglichkeit, ein Verfahren in Russland zu vermeiden, ist die Aufnahme einer Schiedsklausel in den Vertrag. In dieser Klausel werden ein Schiedsgericht sowie die genauen Regeln des Schiedsverfahrens bestimmt. Kommt es nun zum Konflikt, kann, bzw. muss dieses Schiedsgericht vor dem Gang zu einem staatlichen Gericht angerufen werden. Die Mindestgebühr am Schiedsgericht der Stockholmer Handels- kammer beträgt etwa 7.500 Euro. In der Regel wird es aber deutlich teurer: So gibt das Londoner Schiedsgericht LCIA an, dass die durchschnittlichen Gebühren etwa 190.000 US-Dollar betragen. Dennoch liegt der Streitwert am LCIA in den meisten Fällen unter 5 Mio. US-Dollar.

Die Entscheidungen von Schiedsgerichten sind bindend. Die Urteile lassen sich in einer sehr großen Zahl von Ländern durchsetzen: 156 Staaten (darunter auch Russland) haben sich im »New Yorker Übereinkommen über die Anerkennung und Vollstreckung ausländischer Schiedssprüche« grundsätzlich zu einer Umsetzung von Urteilen verpflichtet. Jedoch läuft die Vollstreckung nicht automatisch $\mathrm{ab}$, sondern wird zuerst von einem staatlichen Wirtschaftsgericht des jeweiligen Landes geprüft. Dieses berücksichtigt auch den ursprünglichen Vertrag in seiner Entscheidung. Für die Durchsetzung in Russland muss dieser Vertrag also vor einem russischen Wirtschaftsgericht Bestand haben. Verträge nach ausländischem Recht sind in Russland nur bei Geschäften mit einem "ausländischen Element«, z. B. einem ausländischem Geschäftspartner erlaubt (mehr zur Umgehung dieser Bedingung weiter unten). Wer als russischer Unternehmer den Risiken der heimischen Gerichte vollständig entgehen will, muss also einen Weg zur Durchsetzung im Ausland finden.

Wurde keine wirksame Schiedsklausel vereinbart, bleibt bei einem Konflikt noch die Möglichkeit, vor einem staatlichen Gericht im Ausland zu klagen. Das Londoner Handelsgericht spielt hier eine zentrale Rolle, weil es seine Jurisdiktion im internationalen Vergleich sehr großzügig interpretiert. Voraussetzung für die Eröffnung eines Verfahrens ist die Zustellung der Klageschrift. Dies kann persönlich innerhalb Englands (wie im Fall Beresowskij vs. Abramowitsch) oder über einen gesonderten Antrag auch im Ausland geschehen. Voraussetzung für die Zustellung im Ausland ist, dass das Londoner Gericht eine Verbindung des Falls zu England sieht. Dies kann eine Gerichtsstand-Klausel in dem Vertrag sein, auf den sich die Klage stützt. So klagte die "Russian Commercial Bank«, eine zypriotische Tochter der russischen Staatsbank VTB, im Jahr 2009 in London gegen den russischen Unternehmer Fjodor Choroschilow auf Rückzahlung von Krediten, die für die Exploration von Öl-Lizenzen vergeben wurden. Grundlage waren hier Kreditverträge zwischen Choroschilow und der VTB-Tochter, in denen englisches Recht und England als Gerichtsstand festgelegt waren.

Zuweilen genügt es aber auch, wenn die Verbindung zu England eher indirekt ist. Im Prozess des nach Israel emigrierten Oligarchen Michael Cherney gegen Oleg Deripaska entschied sich das englische Gericht nach einer sehr ausführlichen Abwägung für die Zustellung 
der Klage im Ausland, obwohl die einzige tatsächlich belegte Verbindung zu England war, dass die umstrittene Vereinbarung in einem Londoner Hotel getroffen wurde. Im Fall Cherney vs. Deripaska war für das Gericht Ausschlag gebend, dass Cherney aufgrund der politischen Beziehungen Deripaskas in Russland kein faires Verfahren bekommen würde, ja sogar um Leib und Leben fürchten musste. Grundlage dieser Überzeugung waren wenig schmeichelhafte Gutachten verschiedener Wissenschaftler über das russische Rechtssystem. Der Konflikt mit einem Streitwert von über 1 Mrd. Euro endete schließlich in einer außergerichtlichen Einigung Cherneys mit Deripaska.

Doch nicht nur der weite Interpretationsspielraum bei der Zuständigkeit macht das englische Handelsgericht interessant. Seine Urteile lassen sich außerdem problemlos und quasi automatisch in allen Ländern der EU sowie allen für die russische Wirtschaft wichtigen Offshore-Staaten durchsetzen. Außerdem stehen dem Gericht umfassende Möglichkeiten des vorläufigen Rechtsschutzes zur Verfügung, wie etwa das weltweite Einfrieren von Eigentum (»worldwide freezing order«). Allerdings ist die Durchsetzung der Urteile in Russland nicht möglich, da zwischen England und Russland kein Abkommen über die gegenseitige Anerkennung von Gerichtsurteilen besteht. Deripaska musste den Prozess in London aber aufgrund seiner Investitionen außerhalb Russlands ernst nehmen. Sobald ein russischer Staatsbürger im weiten Zugriffsbereich des englischen Handelsgerichts über Eigentum verfügt, kann er die Urteile dieses Gerichts nicht ignorieren. Erreicht ein russischer Kläger gegen einen im Ausland exponierten Landsmann die Eröffnung eines Verfahrens in London, genießt er damit vollumfänglich die Vorzüge der englischen Rechtssicherheit.

\section{Folgen der Jurisdiktions-Flucht}

Eine sichtbare Folge der Vermeidung der russischen Jurisdiktion ist die tiefgehende Verzahnung der russischen Ökonomie mit Offshore-Standorten im Ausland. Hier sprechen die Direktinvestitions-Statistiken der russischen Zentralbank eine deutliche Sprache: Unter den zehn wichtigsten Quellen von Direktinvestitionen liegt in mindestens sechs Fällen der Verdacht nahe, dass ein maßgeblicher Teil des Kapitals ursprünglich aus Russland kommt. Besonders offensichtlich ist dies im Fall der Republik Zypern: Mitte 2015 stammten mehr als ein Drittel der Direktinvestitionen in Russland aus Zypern (104 Mrd. US-Dollar von insgesamt 303 Mrd. US-Dollar, siehe auch Abbildung unten), während gleichzeitig ein knappes Drittel der russischen Direktinvestitionen im Ausland in Zypern lagen (114 Mrd. von insgesamt 385 Mrd. US-Dollar).
Zwar hat die Bedeutung der Offshores in Russland vielschichtige Ursachen, doch lassen sich einige Zusammenhänge zwischen den Nachteilen des russischen Rechts und der Popularität von Offshores aufzeigen: Viele zypriotische Holdings werden gegründet, um Gesellschaftsformen oder Transaktionen zu realisieren, die nach russischem Recht aus formellen Gründen nicht möglich sind. Außerdem werden OffshoreHoldings von russischen Geschäftspartnern eingesetzt, um die Bedingung des »ausländischen Elements« zu erfüllen und einen Vertrag nach ausländischem Recht in Russland abschließen zu können. Nicht zuletzt fungieren Offshore-Gesellschaften auch als eine Art Faustpfand: Wer sein Eigentum in den Zugriffsbereich der ausländischen Gerichte bringt, ist als Geschäftspartner vertrauenswürdiger. Dagegen ist die Steueroptimierung nur ein sekundäres Motiv.

Die Bedeutung des englischen Rechts hat auch auf dem Markt der russischen Rechtsanwälte deutliche Spuren hinterlassen. Für die lukrative Rechtsberatung bei Fusionen und Übernahmen werden in Russland fast immer ausländische Kanzleien beauftragt. Im renommierten Kanzleien-Ranking von "Chambers and Partners" finden sich für den russischen Markt in dieser Sparte kaum russische Anwaltsfirmen. Wenn die russischen Unternehmen dann im Ausland prozessieren, entgehen den russischen Anwälten zusätzliche Milliardenbeträge: Allein für die Vertretung Abramowitschs im Rechtsstreit mit Beresowskij sollen mehr als 100 Mio. Pfund an Londoner Anwälte geflossen sein. Gleichzeitig ist ein englischer Master of Laws (LL.M.) für die Karriere von russischen Wirtschaftsanwälten unverzichtbar geworden.

Schließlich ist die Möglichkeit der ausländischen Rechtssicherung aufgrund der großen Fixkosten bei Beratung und Prozessen vor allem ein Privileg größerer Firmen. Kleinere Unternehmen müssen mit der Justiz in Russland Vorlieb nehmen, was die Konkurrenz mit den Konzernen erschwert.

\section{Reaktion der Politik}

Die russische Politik sieht die Verwendung des ausländischen Rechts und vor allem den damit verbundenen Einsatz von Offshore-Holdings aus verschiedenen Gründen kritisch. Sind die Offshore-Gesellschaften einmal etabliert, liegt auch die Verlagerung von Gewinnen ins Ausland nahe, wodurch dem russischen Staat Steuern entgehen. Gleichzeitig hat die russische Regierung keine direkte Möglichkeit, die Geschäfte der Russen im Ausland zu regulieren. Zuletzt wird es als Zeichen geopolitischer Schwäche wahrgenommen, wenn Gerichte in Europa über Wohl und Wehe der Kronjuwelen der russischen Industrie entscheiden. Vor allem in Zeiten von 
Wirtschaftssanktionen gilt die dominierende Rolle des ausländischen Rechts als außenpolitische Verwundbarkeit.

Die Verflechtung der russischen Wirtschaft mit Offshore-Standorten hat Putin am 13. Dezember 2012 in seiner Rede an die Föderalversammlung zum ersten Mal ausführlich als "Jurisdiktions-Flucht" problematisiert und gleichzeitig Maßnahmen gefordert, um "unpatriotische» Unternehmer zur Rückkehr zu bewegen (die Politik der De-Ofschorisazija). Putin sprach an dieser Stelle von "neun von zehn Geschäften", die von russischen Unternehmen nach ausländischem Recht durchgeführt würden. Dem entgegen wirken soll das "Gesetz über die DeOfschorisazija«, das zum 1. Januar 2015 in Kraft getreten ist. Es legt fest, dass nicht ausgeschüttete Gewinne, die in Niedrigsteuerländern anfallen, in Russland versteuert werden müssen. Dadurch vergrößert sich zunächst einmal der bürokratische Aufwand für alle Offshore-Strukturen, ganz gleich ob sie zur Steuerminimierung oder zur Nutzung ausländischen Rechts gegründet wurden.

Deutlicher als dieser restriktive Ansatz könnte sich die Reform des russischen Zivilrechts bemerkbar machen, die seit einigen Jahren Schritt für Schritt durchgeführt wird. So gilt seit dem 1. September 2014 eine neue Fassung des Gesellschaftsrechts, in der einige moderne rechtliche Möglichkeiten wie etwa die Gesellschaftervereinbarung einheitlich geregelt sind. Am 1. Juni 2015 traten außerdem neue Regeln im Vertragsrecht in Kraft, die international gängige Institute der Vertragsabsicherung einführen und komplexere Verträge bei Übernahmen und Zusammenschlüssen von Firmen ermöglichen. Durch diese Neuerungen, in denen das englische Recht als Vorlage gut erkennbar ist, wurden einige der formalen Beweggründe für die Jurisdiktions-Flucht behoben.

\section{Fazit}

Die russische Wirtschaft ist heute ohne die massive Nutzung ausländischen Rechts nicht vorstellbar. Vor allem die großen Unternehmen haben in der Vergangenheit stark von der Absicherung durch ausländische Rechtsinstitutionen profitiert. Die Bemühungen der russischen Führung um eine Rückkehr der Unternehmen in die russische Jurisdiktion sind deutlich erkennbar. Mit der Zivilrechts-Reform der vergangenen Jahre hat das russische Recht auf dem Papier deutlich aufgeholt. Darüber hinaus ist der »Import von Rechtssicherheit», wie er momentan stattfindet, über Anwaltshonorare und Prozesskosten im Ausland auch an den Rubelkurs gebunden. Der schwache Rubel könnte das russische Recht also ebenfalls interessanter machen. Auch haben die gegen Russland verhängten Sanktionen für einen kleinen Kreis von Personen deutlich gemacht, dass unter Umständen auch ausländische Holdings von politischen Risiken bedroht sein können.

Eine schnelle Rückkehr der Unternehmen in das russische Recht ist aber trotzdem nicht zu erwarten. Das Misstrauen in die russischen Wirtschaftsgerichte wird nicht ohne weiteres verschwinden, und die Zahlungsbereitschaft für mehr Rechtssicherheit ist weiterhin hoch. Es wird sich noch zeigen müssen, wie die neuen Vorschriften des Zivilrechts in der Praxis gehandhabt werden. Zuletzt ist der weit verbreitete Einsatz des ausländischen Rechts in Russland auch mit Netzwerkeffekten und Pfadabhängigkeiten verbunden. Unternehmen und Anwälte haben sich in den vergangenen Jahren darauf eingestellt und viel in die Strukturen und Kompetenzen investiert, die für die Nutzung des ausländischen Rechts notwendig sind. Vor allem für kleinere Unternehmen bleiben weitere Verbesserungen im heimischen Rechtswesen aber dringend notwendig. Ohne sie ist eine erfolgreiche Modernisierung der russischen Wirtschaft in der Zukunft schwer vorstellbar.

\section{Über den Autor:}

Janis Kluge, Ökonom an der Universität Witten/Herdecke, beschäftigt sich in seiner Doktorarbeit mit der russischen Wirtschaft und ihrer internationalen Verflechtung. Seine Forschungsinteressen sind politische Risiken bei Direktinvestitionen, die Entwicklung von Rechtsstaatlichkeit und die Rolle internationalen Wirtschaftsrechts. Über aktuelle ökonomische Entwicklungen schreibt er regelmäßig in seinem Blog Russianomics.com.

\section{Lesetipps}

- High Court of Justice, Queen’s Bench Division, Commercial Court: Michael Cherney vs. Oleg Vladimirovich Deripaska, [2008] EWHC 1530 (Comm), 3. Juli 2008; <http://www.bailii.org/ew/cases/EWHC/Comm/2008/1530. $\underline{\mathrm{html}} \geq$. (Interessante Begründung des Londoner Handelsgerichts für eine Klagezustellung an Oleg Deripaska außerhalb Englands, insbesondere ab Absatz Nr. 197)

- Steininger, A., D. Olejnik: Schuldrechtsreform in Russland 2015 [=Wissenschaftliche Beiträge des Ostinstituts Wismar, O/L-3-2015], 02. Dezember 2015; <http://www.ostinstitut.de/documents/Steininger_Olejnik_Schuld rechtsreform_in_Russland_2015_OL_3_2015.pdf>. 
Grafik 4: Bestand ausländischer Direktinvestitionen (Richtungsprinzip) zum 1.7.2015

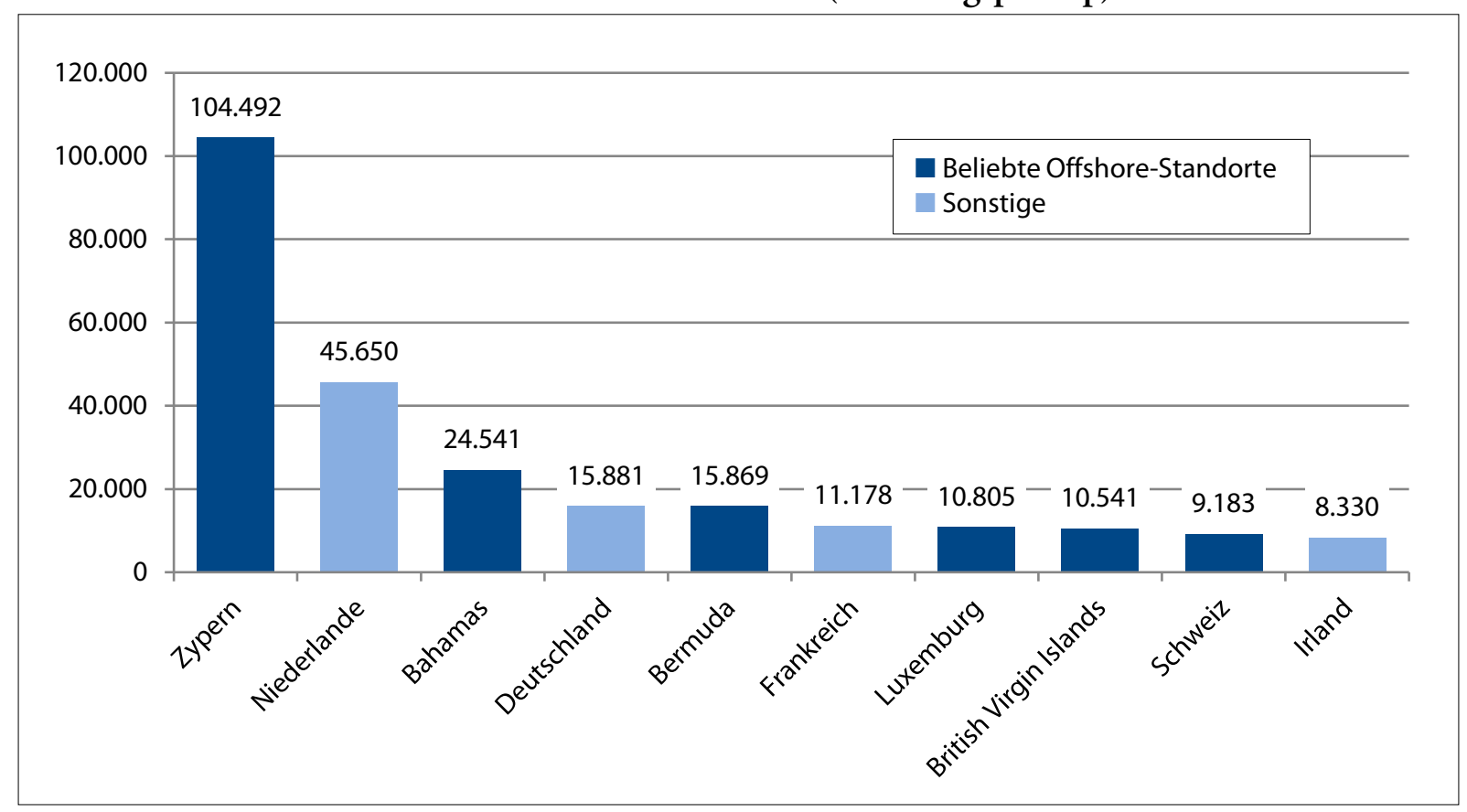

Quelle: Zentralbank der Russischen Föderation; <http://www.cbr.ru/Eng/statistics/?PrtId=svs $\geq$

\section{"Nacht der langen Baggerschaufeln«.}

\section{Zur Debatte über den Abriss von Kiosken in Moskau}

In der Nacht vom 8. auf den 9. Februar führte die Moskauer Verwaltung eine Säuberungsaktion gegen angeblich illegal errichtete Kleinläden und Imbissbuden durch, die seit den 1990er Jahren das Bild der russischen Hauptstadt prägen. In Begleitung der Polizei wurden Dutzende Kiosks und Pavillons innerhalb von wenigen Stunden trotz Proteste der Besitzer und Mitarbeiter von Bulldozern abgerissen. Obwohl viele Moskauer sich seit Langem über die Kleinläden mit Billigwaren und Imbissbuden fragwürdiger Qualität beschweren, stieß das Vorgehen von Bürgermeister Sergej Sobjanin auf viel Kritik, weil er trotz zahlreicher Gerichtsentscheide per Erlass in einer Nacht- und Nebelaktion Tausenden Ladenbesitzern ihre Existenzgrundlage entzog. Der Kreml unterstützte das entschlossene Vorgehen Sobjanins. Der Leiter der Präsidialadministration Sergej Iwanow sprach sich in einem Interview mit RIA Nowosti strikt gegen das Weiterbestehen von Billigläden an Metrostationen aus: „Diese hässlichen Buden haben mit sogenanntem Kleinunternehmertum nichts zu tun, weil sie in der Regel Nährboden für Kriminalität und unhygienische Bedingungen sind «. (<http://ria.ru/moscow/20160211/1372819779.html>). Aber auch einige Oppositionsvertreter fanden die Aktion der Moskauer Regierung angemessen. Die Fernsehmoderatorin Ksenija Sobtschak schreibt, sie sei trotz des rechtswidrigen Vorgehens für den willkürlichen Abriss der hässlichen Bauten, weil man sie sonst aus Moskau nie loswerde. Das russische Netz diskutiert über die "Nacht der langen Baggerschaufeln«, die einmal mehr das Recht auf Eigentum in Russland in Frage stellte. Neben Sobtschak meldeten sich u. a. zu Wort: Walerij Solowej, Historiker und Professor an der Moskauer Staatlichen Hochschule für Internationale Beziehungen (MGIMO), Eduard Birow, Journalist der kremlnahen Zeitung »Wsgljad«, Georgij Alburow, Jurist der Stiftung für Korruptionsbekämpfung, und Leonid Nikitinskij, Journalist, Bürgerrechtler und Mitglied des Menschenrechtsrates beim Präsidenten. 


\section{Sobjanin: Bringe Moskau den Moskauern zurück}

"Der Abriss illegaler Bauten in Moskau ist ein anschauliches Beispiel dafür, dass in Russland die Wahrheit, das Erbe und die Geschichte unseres Landes nicht zum Verkauf stehen. Die sollen sich nicht hinter Eigentumpapieren verstecken, die offensichtlich ergaunert wurden. Wir werden Moskau den Moskauern zurückbringen. Seine offenen, schönen und geliebten Grünanlagen, Plätze und Straßen.»

Sergej Sobjanin am 10. Februar 2016 auf »V Kontakte«; <https://vk.com/mossobyanin?w=wall265870743_15755>

\section{Solowej: Diese Macht hasst Kapitalismus und Freiheit}

"Warum werden die Kioske in Moskau abgerissen?

Es liegt in der Natur unserer russischen Staatsmacht. Ganz offen hasst sie alles, was sie nicht kontrollieren kann. Kleine und mittlere Unternehmen sind genau das, was Lenin als »kleinbürgerliche Naturkraft, die stündlich den Kapitalismus erzeugt«, bezeichnet hat. Der Gencode dieser Macht ist kommunistisch. Sie hasst Kapitalismus. Und die damit verbundene Freiheit."

Walerij Solowej am 9. Februar 2016 auf»Facebook«; <https://www.facebook.com/permalink.php?story_fbid =168052 0878884958\&id=100007811864378>

\section{Birow: Das Krämer-Russland geht, das imperiale Russland kehrt zurück}

"Die massenhafte Beseitigung von Kiosken in Moskau ist nicht das erste, aber ein symbolträchtigstes Zeichen der strukturellen Änderungen im russischen Staat. Das Krämer-Russland geht, das imperiale Russland kehrt zurück. Kleinliche Einzelinteressen von Privatunternehmern machen staatlicher Ordnung und hehren Träumen der großen Nation Platz.

In dem liberalen prowestlichen Milieu, das persönliche Bereicherung und eigene Unverantwortlichkeit den Volksinteressen vorzieht, gilt dies als ein Angriff der Großmacht-Tyrannei auf die Rechte der freien Persönlichkeit [...]

Wie üblich mit der Hauptstadt beginnend, reinigt sich Russland von den pseudo-baukünstlerischen Ablagerungen des wilden Kapitalismus, macht Straßen, Alleen und Plätze frei, um die Bürger allein schon mit diesem Anblick wieder an das imperiale Selbstgefühl, an Weite und Herrlichkeit zu erinnern.

Der städtische Raum, der plötzlich nun unter den "Shanghais« der Händler wieder zum Vorschein kommt, fasziniert durch seine Perspektive und versetzt einen gedanklich in die Höhen Puschkins und Peters [des Großen]. Die monumentalen massiven Gebäude wiederum erinnern an die tausendjährige, wenn auch nicht immer einfache, so doch große heimatliche Geschichte. [...]

Eduard Birow am 10. Februar 2016 in "Wsgljad«; <http://vz.ru/opinions/2016/2/10/793479.html>

\section{Alburow: Wie populäre Initiativen durch Lüge scheitern}

"Es ist natürlich unfassbar, wie es die Moskauer Regierung hinbekommen konnte, sich bei dieser wichtigen und gefragten Sache, dem Abriss all der verdammten Kioske, öffentlich so abgrundtief zu blamieren.

Alles hätte so einfach sein können: Gehen Sie vor Gericht, und wenn das Gericht eine Absage erteilt, kaufen Sie alles zu Marktpreisen und machen damit, was Sie wollen. Alle würden das unterstützen, allen würde es gefallen. Sobjanin wäre ein Held.

Aber verdammt nochmal, nein. Es mussten zuerst Lügen über "Samostroj« [ungenehmigter Eigenbau] in die Welt gesetzt werden, über den Zugang zu Versorgungsleitungen (Hallo! Irgendwie hatte es 20 Jahre lang keinerlei Probleme mit dem Zugang gegeben), über die Einsturzgefahr der Unterführungen (auch hier: 20 Jahre war nichts passiert), über "Gefahr von Terroranschlägen« usw.

Nach diesen Lügen folgte bereits eine Kettenreaktion: Da man schon über Versorgungsleitungen und Terroranschläge gelogen hatte, musste man erklären, dass es dort keine Kioske mehr geben werde, sondern nur Parkanlagen. Am nächsten Tag stellte sich jedoch heraus, dass es nicht zu knapp Kioske geben wird, sogar Shopping-Zentren, allerdings die eigenen!

Auch auf die Frage des »Samostroj« musste eine Antwort gegeben werden. Natürlich wurde umgehend festgestellt, dass alle Objekte registriert waren, sie waren vom Staat offiziell abgenommen, hatten Katasternummern und waren überhaupt Privateigentum. Worauf Sobjanin mit dem schon legendären "Die sollen sich nicht hinter Eigentumspapieren verstecken« antwortete. Nach solchen Worten wäre jedem Politiker in jedem zivilisierten Land der Weg zu einem gewählten Amt für immer versperrt [...].« Georgij Alburow am 11. Februar 2016 auf Facebook; <https://www.facebook.com/alburov/posts/973506626074163> 


\section{Sobtschak: Zwischen Gesetz und Willkür haben wir keine Wahl}

"[...] Die Entscheidung, Kioske abreißen zu lassen, ist keine Dummheit. Hier unterstütze ich Sobjanin vollkommen. In diesem Dilemma - den trostlosen Scheiß dem Gesetz gemäß zu dulden oder alles in Willkür abzureißen - bin ich für die Willkür, einfach, weil ich gegen den Scheiß bin.

Ja, Rechtslosigkeit ist furchtbar. Es gibt jedoch keine großartig andere Wahl. Ist es wirklich besser in einem ewigen Basar zu leben, der sich nie ändern wird? Welche Alternativen hätte die Stadt noch?

Wohl keine, denn all das wurde gekauft, registriert und legalisiert lange bevor Sobjanin Bürgermeister wurde oder in den ersten Jahren seiner Amtszeit. Jetzt - das weiß ich aus eigener Anschauung genau - ist dieses Korruptionsgeschäft vollständig gestoppt. Gegen kein Geld der Welt und mithilfe keinerlei Absprache kann man einen Kiosk errichten. Leute, die solche Fragen auf diese Weise klären könnten, gibt es in Moskau heute nicht mehr. Von daher ist es sinnvoll, was Sobjanin gemacht hat. Er hat die Korruptionsmethoden zum Aufbau von Kiosken, gläsernen Buden und Anbauten zerstört. Er will wirklich das Stadtbild verändern. Das lässt sich schlecht realisieren, wenn gleichzeitig provisorische Läden mit synthetischen Strumpfhosen und Piroggen mit Katzenfleischfüllung beibehalten werden.

Mich empört die Heuchelei der Internet-Öffentlichkeit, ihre doppelten Standards. Sind Sie für das Gesetz? Gefallen Ihnen das "Dima-Jakowlew-Gesetz« [Gesetz über ein Verbot der Adoption russischer Waisenkinder durch amerikanische Staatsbürger; d. Red.], das NGO-Gesetz, die Gesetze über Demonstrationen? Oder akzeptieren Sie womöglich, dass manche Gesetze keineswegs zu positiven Veränderungen im Land beitragen?

Vielleicht dürfen nur diejenigen schädliche und hämische Gesetze verletzen, mit denen Sie über Facebook befreundet sind? Als Ihr lieber Kapkow [ehemaliger Leiter des Gorki-Parks und Leiter der Kulturabteilung in der Moskauer Regierung; d. Red.] Schaschlik-Buden im Gorki-Park abreißen ließ, freuten Sie sich, applaudierten und lagen ihm zu Füßen. Kapkow machte aber genau das Gleiche, was heute Sobjanin unternimmt. [...]

Ja, es stimmt: In Willkür. Ja, in einer Nacht. Ja, ohne Vorwarnung. Das ist ein sehr trauriger aber im heutigen Russland unvermeidlicher Ablauf der Ereignisse. Es kann leider nur so funktionieren. Wir haben keine Wahl zwischen Gesetz und Willkür. Die Wahl ist eine andere: in Willkür zwischen Verunstaltung und Misere zu leben oder wiederum unter Umgehung des Gesetzes - zu versuchen, irgendetwas Besseres zu erreichen."

Ksenija Sobtschak am 11. Februar 2016 auf Snob.ru <https://snob.ru/selected/entry/104423>

\section{Nikitinskij: »Unter den Baggerschaufeln brach das Gericht zusammen«}

"[...] Vor lauter schepperndem Glas, polternden Ziegelsteinen und dem Heulen des pleitegehenden Kleinbürgertums haben wir nicht mal gemerkt, wie in Moskau die Judikative verstorben ist. Leise und unmerklich. Insofern, hat die Moskauer Regierung, die den Erlass Nr. 829-PP verabschiedete, diesen einfach außer Acht gelassen. Das Gericht wurde vergessen und man hat es geschlagen. "Später wird es [per Gericht] bestätigt werden«. Genauso agieren stets auch die "Rechtsschutzbehörden«: Wir haben jemanden eingelocht - sie werden es schon bestätigen. [...] «

Leonid Nikitinskij am 13. Februar 2016 in der »Nowaja Gaseta«; <http://www.novayagazeta.ru/columns/71841.html>

Ausgewählt und zusammengefasst von Sergey Medvedev, Berlin (Die Blogs, auf die verwiesen wird, sind in russischer Sprache verfasst) 


\section{Nach Putin}

Jens Siegert, Moskau

$\mathrm{D}$ ie Wirtschaftskrise hat Russland weiter fest im Griff. Seit 2014 sind die Realeinkommen im Land um mehr als 15 Prozent gefallen. Der Rubel ist heute, in US-Dollar oder Euro gerechnet, nur noch die Hälfte dessen wert, was man noch Ende 2014 für ihn bekam. Das Durchschnittseinkommen ist in der gleichen Zeit von gut 800 US-Dollar im Monat auf weniger als 400 gesunken. Rein statistisch ist das der Abstieg von einem Schwellenland mit Blick nach oben zu einem armen Land mit Blick nach unten.

Trotzdem ist von politischer Krise nichts zu spüren. Putin scheint fester im Sattel zu sitzen als je zuvor. Die Soziologen vom Lewada-Zentrum wollen in ihren Langzeitbeobachtungen »die Möglichkeit von Unzufriedenheit« in ein oder zwei Jahren ausmachen. Das war es dann auch schon. Von Unruhe, ja gar Palastrevolte oder Volksaufstand keine Spur.

Gleichzeitig ist die politische Elite rund um den Kreml hochnervös. Die Zeit des großen Verteilens (die großen Brocken werden innerhalb der Elite verteilt, kleinere aber auch im gemeinen Volk) ist vorbei. Die Dumawahlen im kommenden September und die Präsidentenwahlen in zwei Jahren werfen ihre Schatten voraus. Die Angst, Volkes Unmut könnte sich doch an den Wahlurnen zeigen, ist trotz aller Sicherungsmaßnahmen (also die fast totale Kontrolle über die politischen Parteien und die Massenmedien, ebenso wie die Abschaffung unabhängiger Wahlbeobachtung) groß. Jede Form von unabhängiger Opposition, ja jede Form von Unabhängigkeit im Land wird deshalb eifersüchtig verfolgt, einzuschüchtern versucht und klein gehalten, egal ob es sie nun wirklich gibt (eher wenig) oder ob sie eingebildet ist (davon scheint es jede Menge zu geben).

Nach außen benimmt sich das Land weiter nach dem Motto: »Ihr habt uns alle beleidigt und nun machen wir euch überall das Leben so schwer wie möglich, damit ihr uns wenigstens deshalb ernst nehmt«. Das klappt ziemlich gut. Die Rede von Premierminister Medwedew auf der Münchner Sicherheitskonferenz vorige Woche wirkte mit ihrem »neuen Kalten Krieg« und ihrer "dritten Welterschütterung" wie ein Wiedergänger der berühmten Putin-Rede von 2007. Allerdings dominierte bei den Reaktionen damals im Westen noch eine gewisse Ungläubigkeit. Diesmal war es eher die beunruhigte und auch ein wenig resignierte Feststellung, dass das noch lange andauern wird.

Nach den vergeblichen Protesten gegen Wahlfälschungen im Winter 2011/2012 und Putins Wiederwahl im März 2012 kursierte in Russland folgender
Witz: Puschkin ist unser ein und alles, Putin ist unser jetzt und für immer. Dass Putin sich 2018 zur Wiederwahl stellen wird, bezweifelt kaum jemand (auch wenn momentan in Moskau erzählt wird, Putin könnte versuchen, sich bis dahin mit dem Westen auf einen neuen, wegen Syrien und der Flüchtlinge für Russland günstigen modus vivendi zu einigen, um dann als Sieger abzutreten und seinen Nachfolger - wer auch immer es seimit den Problemen allein zu lassen). Warum sich also mit der Frage beschäftigen, was (oder besser: wer) nach Putin kommt und warum es (oder er) kommen könnte?

Die Antwort gibt ein kleiner Blick zurück. Vor knapp einem Jahr (wer erinnert sich noch daran?) war Präsident Putin plötzlich und völlig ungewohnt aus der Öffentlichkeit verschwunden. In den ersten Tagen verbreitete das staatliche Fernsehen noch Bilder von angeblichen Treffen mit diesem und jenem. Aber schon bald kam heraus, dass es sich dabei um Konserven handelte. Schnell war das ganze Land (und mit ihm erhebliche Teile der übrigen Welt) damit beschäftigt, sich auszudenken, was denn nun dahinterstecke und was es bedeute, wenn Putin wahlweise krank, amtsmüde oder gar tot sei. Auch ich befasste mich mit der Frage: $<$ http://russland. boellblog.org/2015/03/15/was-kommt-nach-putin-undwie-kommt-es/>. Nach zehn Tagen tauchte Putin wieder auf. Der Kreml tat, als sei nichts geschehen, aber das konnte und kann nicht darüber hinwegtäuschen, dass das System ohne Putin nicht funktioniert.

Nun versuchen uns der Kreml und Kremlfreunde (auch im Westen) schon seit über 15 Jahren weiß zu machen, dass, egal was oder wer nach Putin kommen kann, es ohne ihn nur (noch) schrecklicher werden kann. So sei Russland, so sei das russische Volk eben. Man werde sich dann noch nach Putin zurücksehnen, ist die Botschaft. Das ist natürlich nicht auszuschließen. Ausgemacht ist es aber auch nicht. Überhaupt finde ich solche Spekulationen eher müßig: Darüber nachzudenken, ob nun Verteidigungsminister Schojgu einen Militärcoup plant, Vizepremier Rogosin vorhat, ein ultranationalistisches Regime anzuführen und den eurasiatischen Wirrkopf Alexander Dugin zum Premierminister zu machen, oder ob Ministerpräsident Medwedew, endlich von Putin befreit, doch noch den Liberalen in sich zeigen und Russland in demokratische Fahrwasser zurück lotsen wird, hat, über den Tag hinaus, kaum analytischen (Mehr)Wert.

Ich möchte daher lieber versuchen, ein paar längere, grundsätzlichere Linien nachzuzeichnen. Zunächst ein paar allgemeine Bemerkungen: 
Es ist gute und geschichtlich geprüfte deutsche Wahlkampfweisheit, dass (fast) nie neue Regierungen ins Amt gewählt, sondern (fast) immer nur alte Regierungen abgewählt werden. Man muss als Politiker also schon ziemlich viel Mist machen, bevor man die Macht wieder verliert. Deutschland ist eben ein im Grunde sehr konservatives Land. Russland ist das auch, vielleicht sogar noch mehr. Zumal hier die Gewöhnung an ständigen und großen staatlichen Mist zu einer gewissen Resignation geführt hat. Bevor es in Russland einen politischen Wechsel gibt, bedarf es deshalb nicht nur einer, sondern sogar mehrerer handfester Krisen (eine, die Wirtschaftskrise, haben wir ja längst); aber es bedarf auch und vor allem einer personellen Alternative. Die gibt es nicht. Da sind sich alle einig.

Nun ist es eine der hervorragendsten, ja vielleicht die hervorragendste und mit vielen Ressourcen unterfütterte Beschäftigung des Kremls, sie auch gar nicht erst auftauchen zu lassen. Klassischerweise stehen drei Instrumente zur Sicherung politischer Herrschaft bereit: politische, durch Verfahren und Institute vermittelte Legitimität, wirtschaftliches Wohlergehen und Gewalt. Putin hat in den 2000er Jahren erfolgreich eine ausgewogene Mischung aus allen drei Elementen praktiziert, wobei mit der Zeit die demokratische Legitimität geringer und die staatliche Gewalt größer wurde. Abgefedert hat diese Gewichtsverschiebung der stetig wachsende Wohlstand.

Als es dann aber, ab 2008/2009, mit der Wirtschaft bergab ging und die Legitimität durch die Rochade Putin-Medwedjew-Putin vor allem unter der gut gebildeten und städtischen Bevölkerung weitere tiefe Kratzer bekam, versuchte es Putin - bis heute erfolgreich mit noch mehr Gewalt nach innen und nach außen. Die innere Gewalt dient der direkten Herrschaftssicherung, die äußere ersetzt (massiv propagandistisch unterfüttert) die abhanden gekommene demokratische Legitimität durch populistische Zustimmung.

So weit sind das alles konventionelle Herrschaftstechniken, durchaus mit Geschick und auch Fortune gehandhabt. Ein paar Blicke in die sowjetisch-russische Geschichte zeigen aber schnell, dass Putins Vorgänger das ebenso konnten - und es trotzdem irgendwann nicht mehr reichte. Es musste und muss bei langer Herrschaft immer noch etwas hinzukommen, das man »im Zeitgeist bleiben « nennen könnte. Anders ausgedrückt, muss sich politische Herrschaft, so sie sich nicht ausschließlich auf Gewalt stützt (und das hat auch in der Sowjetunion/Russland seit Stalin niemand mehr wirklich versucht) immer wieder modernisieren, ja von Zeit zu Zeit in gewisser Weise neu erfinden. Bisher gelingt das Putin. Doch nun, wie versprochen, zu den Vorgängern.

Ich fange mit Leonid Breschnjew an, weil er zum einen aktiv, also nicht durch den Tod seines Vorgän- gers an die Macht gekommen ist, und zum anderen, für einen Sowjetführer mit bis dahin erstaunlich wenig Gewalt regiert hat. Gerade das war vielleicht sein Erfolgsgeheimnis. Nach Bürgerkrieg, stalinistischem Terror, Krieg, fortgesetztem stalinistischem Terror und der Chruschtschowschen Mischung aus Tauwetter und immer heißer werdendem Kaltem Krieg wollten viele Menschen in der Sowjetunion vor allem Ruhe, eine gewisse Beständigkeit und ein bescheidenes Auskommen, also vor allem keinen Hunger mehr. Breschnjew lieferte das so gekonnt, dass die 1970er Jahre in der Erinnerung vieler Menschen in Russland bis heute als das goldene Jahrzehnt erscheinen. Die Ruhe geriet aber so perfekt, dass das Land bald im sprichwörtlich gewordenen »Sastoj« (deutsch: "Stillstand») erstarrte. Mitte der 1980er Jahre hatten immer mehr Menschen in der Sowjetunion genug davon. Sie wollten wieder Bewegung. Die kam dann auch, als in schneller Folge drei tote Generalsekretäre (und ein katastrophal niedriger Ölpreis) die Lebensunfähigkeit des Systems deutlich machten.

Dem Geist der Zeit entsprang nun mit Michail Gorbatschow ein mit 54 Jahren verhältnismäßig junger, vor allem aber ungewohnt dynamischer und auf moderne Art kommunikativer neuer Chef. Gorbatschow versuchte den verknöcherten Staat zu öffnen (»Glasnost») und umzubauen (»Perestrojka»). Im Nachhinein erscheint diese Aufgabe wie ein gordischer Knoten: Ihn aufzudröseln war niemand in der Lage (und hatte auch nicht die Zeit dazu). Ihn wie Alexander der Große durchzuhauen, hätte Kräfte freigemacht, die kaum zu bändigen gewesen wären. Gorbatschow versuchte ein Mittelding. Doch selbst seine vorsichtige Öffnung beraubte den auf (totale) Kontrolle angelegten Staat seiner Fähigkeit, den Umbau zu lenken. Das Land geriet außer Kontrolle (seiner Herrscher).

Heute gilt Michail Gorbatschow vielen Menschen in Russland als Verräter am Staat, weil er dessen (damals immer noch enormen) Gewaltmittel nur sehr zögernd gegen die Freiheitsgeister eingesetzt hat. Gleichzeitig hat er sich aber auch nicht dazu entscheiden können, entschieden auf diese Freiheitsgeister zu setzen.

Das tat erst sein Nachfolger Boris Jelzin, der 1991 durch die wohl bis heute freiesten Wahlen der russischen Geschichte ins Amt gelangte. Jelzin, obwohl auch er ein Mann des kommunistischen Parteiapparats war, gab der Freiheit vollen Lauf. Er tat das wohl weniger aus Überzeugung, denn aus Machtkalkül. Andererseits gehört er (wie übrigens auch Gorbatschow) zur Generation der in Russland sogenannten 60er. Sie ist mit dem stalinistischen Terror in der 1930er Jahren aufgewachsen, hat den Krieg als Heranwachsende erlebt und war treibende Kraft des Tauwetters nach Stalins Tod. Auch viele Dissidenten der ersten Stunde kamen aus dieser Generation. 
Viele Menschen in Russland empfinden die 1990er Jahre inzwischen als eine Zeit des Chaos und des Staatszerfalls (die staatliche Propaganda inspiriert und stützt dieses Gefühl). Jelzins Versprechen auf Freiheit und Beteiligung, sicher mehr aus Not geboren (aus der Not an der Macht zu bleiben, aber auch aus der Not, Land und Wirtschaft zusammen zu halten) denn aus Überzeugung, mutierte ja tatsächlich recht schnell zu einer Mischung aus Willkür und Schlamperei. Der Staat zog sich nun aber nicht nur aus dem Privatleben seiner Bürger zurück, sondern auch aus ihrem Leben und damit aus der ihm obliegenden Daseinsvorsorge der Menschen insgesamt. Und diskreditierte damit in Russland diese beiden Grundbestandteile von Demokratie bis heute gründlich.

Das Pendel schlug zurück und mit Putin tauchte ein neuer Herrscher auf. Er versprach anfangs das Beste aus beiden Welten: den Staat erneut zu stärken, ohne ihn zu verknöchern. Putin bediente zunächst zwei Bedürfnisse: das nach Ruhe und Ordnung ebenso wie das nach einer Pause bei den Veränderungen. Oder besser gesagt: Er schaffte es, (notwendige) Veränderungen wie Stabilität wirken zu lassen. Die wirtschaftliche Konjunktur, also vor allem der im Eiltempo steigende Ölpreis, half hier enorm. Dann erlahmte die Konjunktur und der Versuch, es erneut offensiv mit Veränderung, der Medwedjewschen Modernisierung, zu probieren, ging schief.

Putin wandte nun ein in der russischen (und nicht nur dort) Politik schon oft erfolgreiches Mittel an: nationale Mobilisierung gegen innere und äußere Feinde (wobei fast egal ist, ob es die tatsächlich gibt). Bisher funktioniert das, erst mit der Krim und der Ostukraine, nun mit Syrien, jedenfalls gemessen an der in Umfragen ermittelten Zustimmung, ganz gut.

Aber wenn dieser kleine Abriss den geschichtlichen russischen Pendelschlag zwischen Freiheit und Kontrolle richtig beschreibt, dann müssten die unruhigen, gegen zu viel und zu starren Staat gerichteten Kräfte in Russland bald wieder stärker werden. Auch deshalb scheint mir die Drohung, nach Putin könne alles nur noch schlimmer werden, eine leere zu sein.

Einen kleinen Hinweis darauf gibt auch Putin selbst. Der Krieg in Syrien ist der erste mit russischer Beteiligung nach "westlichem « Muster: Bomben aus der Ferne und aus der Luft mit möglichst geringem Risiko für die eigenen Soldaten, keine Bodentruppen. Auch der russische Staat unter Putin kann oder will es sich offenbar nicht mehr leisten, mit den Leben seiner Bürger allzu leichtfertig umzugehen. Egal, ob das nun daran liegt, dass die Menschen sich in den vergangenen 30 Jahren untergründig doch mehr geändert haben (und viele von ihnen wirklich zu Bürgern geworden sind) oder (einfach nur) daran, dass der Staat nicht mehr so viele von ihnen zur Verfügung hat oder an der weiter sehr frischen Erinnerung an den Krieg in Afghanistan: auch jeder Nachfolger von Putin wird damit rechnen müssen.

Diesen und andere Texte finden Sie auf Jens Siegerts Russlandblog < http://russland.boellblog.org/>. 


\section{Demokratie in Russland}

\section{Grafik 5: Existiert in Russland heute eine Demokratie?}

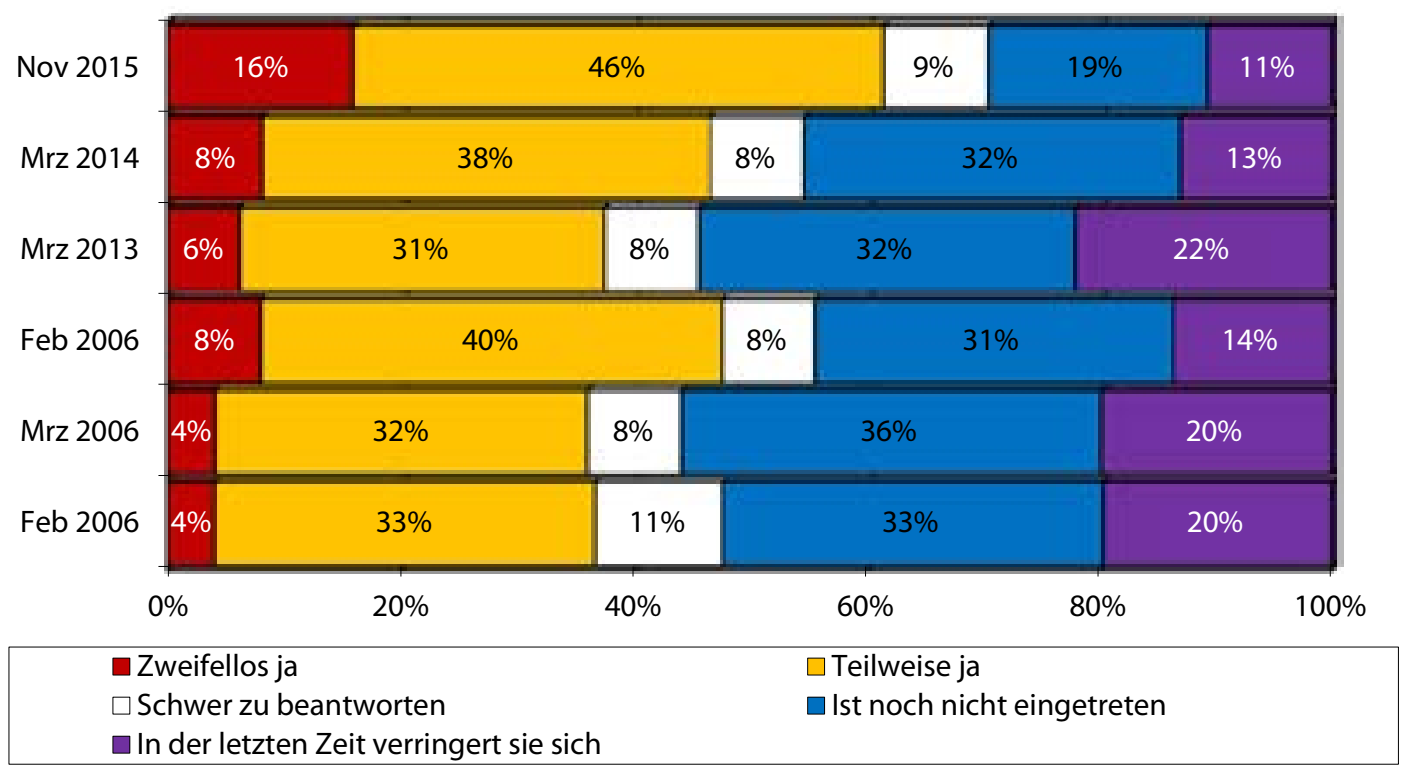

Quelle: Repräsentative Meinungsumfrage des Lewada-Zentrums im Zeitraum vom 20.-23. November 2015; N=1600; <http://www. levada.ru/2016/01/14/rossijskaya-demokratiya/>, 14. Januar 2016

Grafik 6: Was für eine Demokratie braucht Russland?

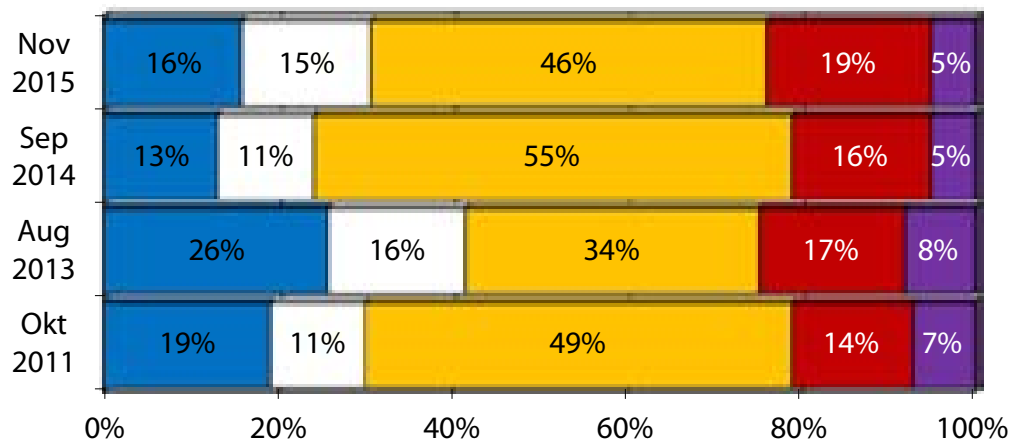

$\square$ So eine, wie in den entwickelten Ländern Europas und Amerikas

$\square$ Keine Antwort

$\square$ Eine besondere, die den nationalen Traditionen und der Spezifik Russlands entspricht

$\square$ Eine wie zu Zeiten der Sowjetunion

Russland braucht keine Demokratie

Quelle: Repräsentative Meinungsumfrage des Lewada-Zentrums im Zeitraum vom 20.-23. November 2015; N=1600; <http://www. levada.ru/2016/01/14/rossijskaya-demokratiya/>, 14. Januar 2016 
Grafik 7: Was für eine Art Staat würden Sie gerne in Zukunft in Russland sehen?

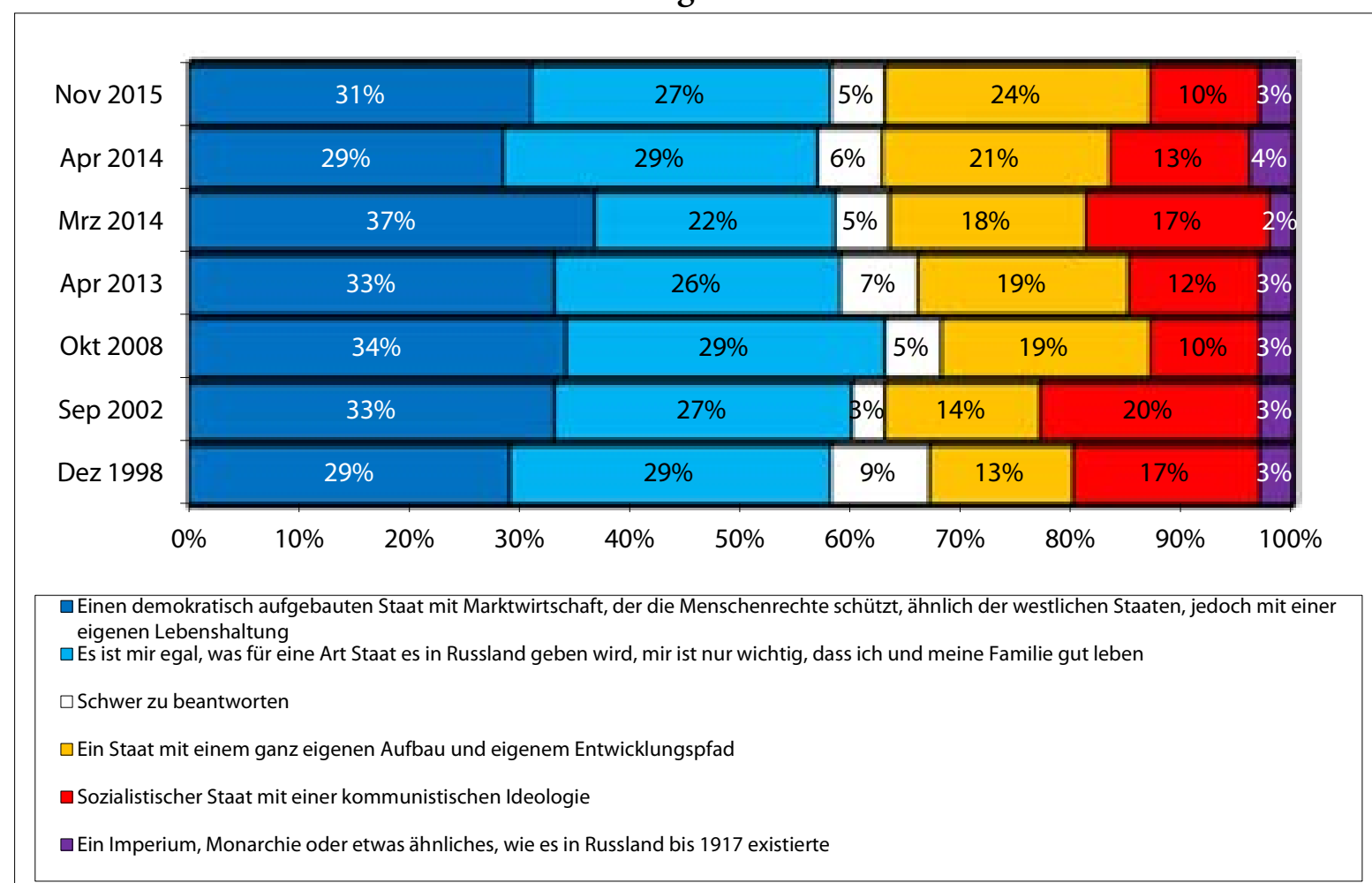

Quelle: Repräsentative Meinungsumfrage des Lewada-Zentrums im Zeitraum vom 20.-23. November 2015; N=1600; <http://www. levada.ru/2016/01/14/rossijskaya-demokratiya/>, 14. Januar 2016

\section{Die wirtschaftliche Lage im Januar 2016}

Grafik 8: Ist die wirtschaftliche Lage in Russland, Ihrer Meinung nach, derzeit gut, zufriedenstellend oder schlecht?

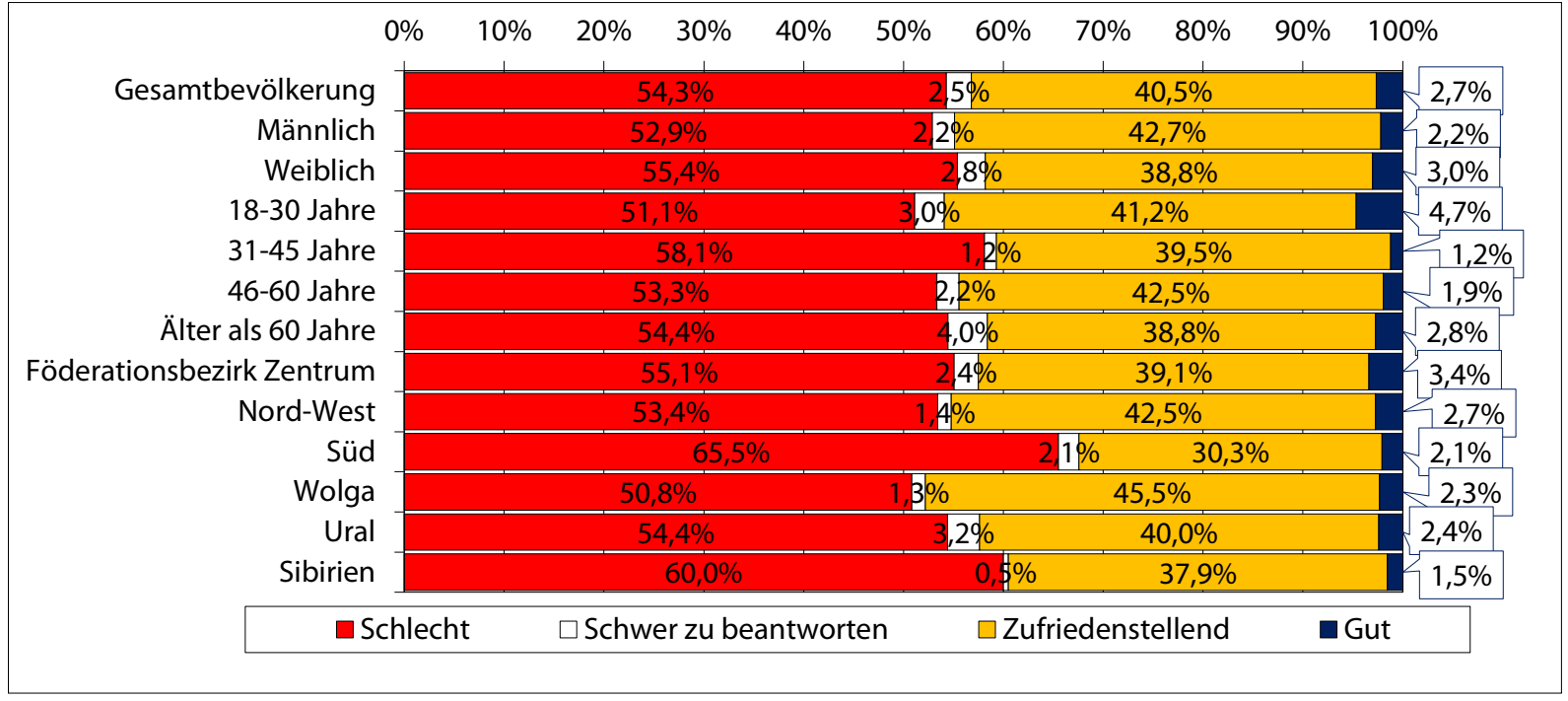

Quelle: Repräsentative Umfrage des Meinungsforschungsinstitut FOM im Zeitraum vom 30.-31. Januar 2016; N=1500; <http://fom. ru/Ekonomika/12513>, 11. Februar 2016 
Grafik 9: Verändert sich, Ihrer Meinung nach, die wirtschaftliche Lage im Land in der letzten Zeit oder nicht? Und wenn sie sich verändert - dann zum Besseren oder Schlechteren?

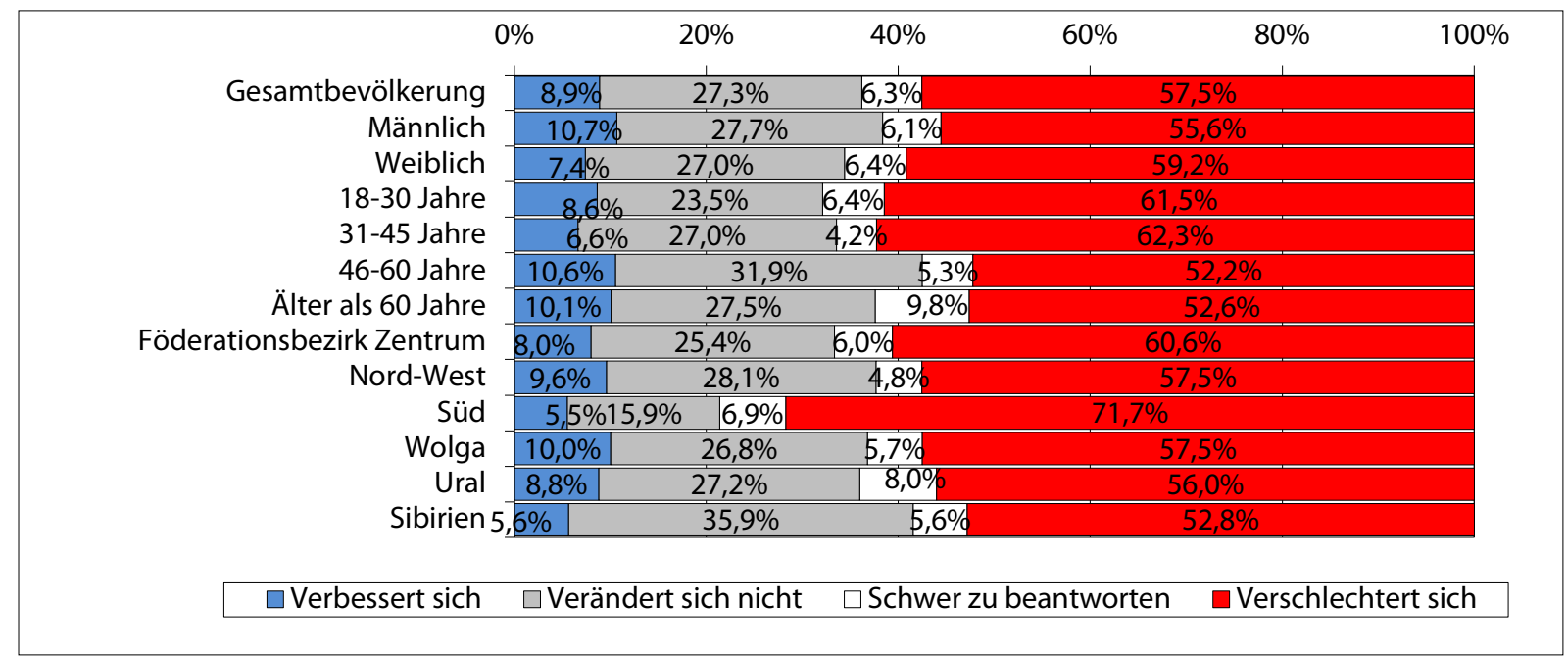

Quelle: Repräsentative Umfrage des Meinungsforschungsinstitut FOM im Zeitraum vom 30.-31. Januar 2016; N=1500; <http://fom. ru/Ekonomika/12513>, 11. Februar 2016

\section{Die dringendsten Probleme}

Grafik 10: Welche Probleme schätzen Sie als bedeutendste für das Land als Ganzes ein? (geschlossene Frage, nicht mehr als 5 Antwortmöglichkeiten)

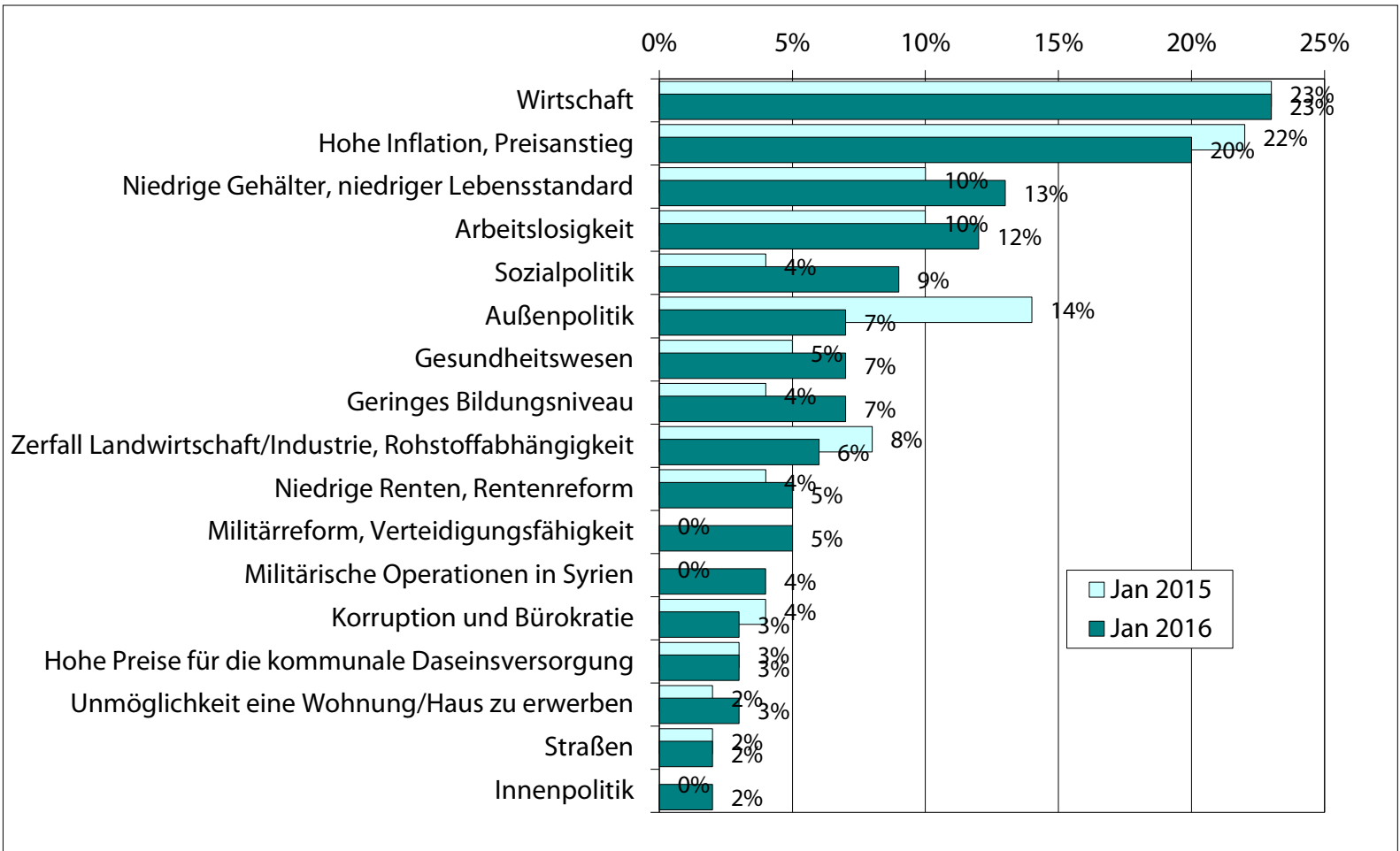

Quelle: Repräsentative Umfrage des Meinungsforschungsinstitut WZIOM im Zeitraum vom 23.-24. Januar 2016; N=1600; <http:// wciom.ru/index.php?id=236\&uid=115568>, 2. Februar 2016 


\section{Werte und Wertewandel}

Grafik 11: Sind Sie einverstanden damit, dass... (geschlossene Frage, eine Antwortmöglichkeit; aufgeführt sind die positiven Antworten)

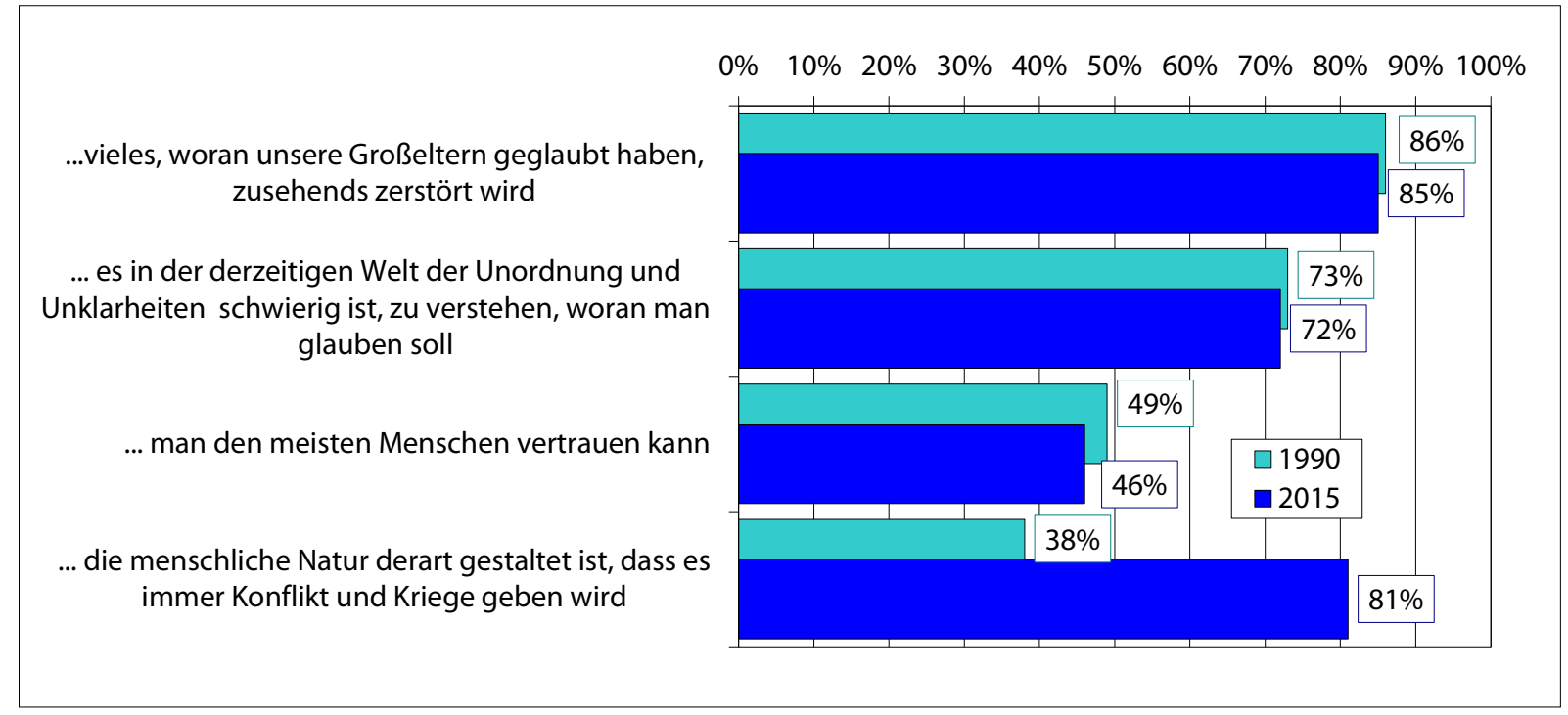

Quelle: Repräsentative Umfrage des Meinungsforschungsinstitut FOM im Zeitraum vom 14.-15. November 2015; N=1600; <http:// wciom.ru/index.php?id=236\&uid=115572>, 5. Februar 2016

Grafik 12: Was denken Sie, sind die meisten Menschen bereit anderen zu helfen oder denken sie eher an sich selbst?

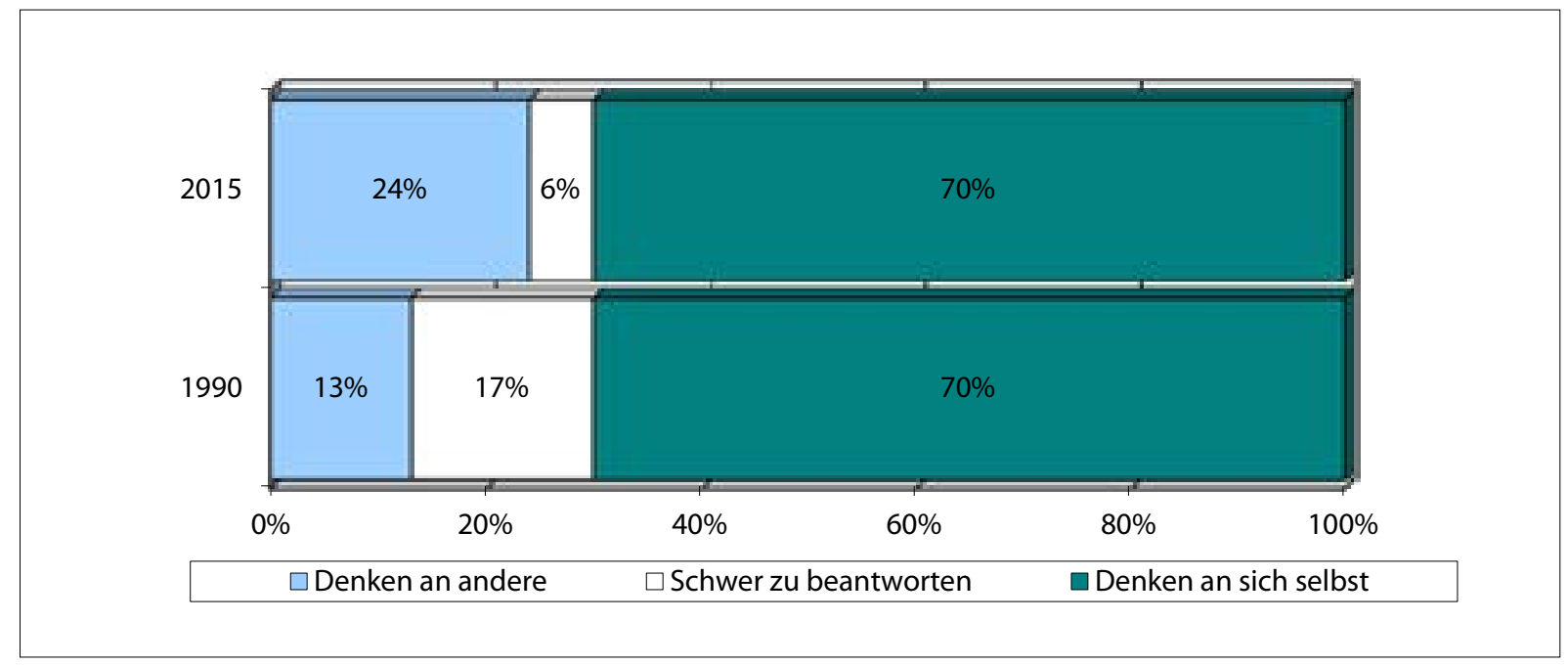

Quelle: Repräsentative Umfrage des Meinungsforschungsinstitut FOM im Zeitraum vom 14.-15. November 2015; N=1600; <http:// wciom.ru/index.php?id=236\&uid=115572>, 5. Februar 2016 
Grafik 13: Was denken Sie, müssen Gesetze ohne Ausnahme eingehalten werden oder sollte man sich eher nach seinem Gewissen richten?

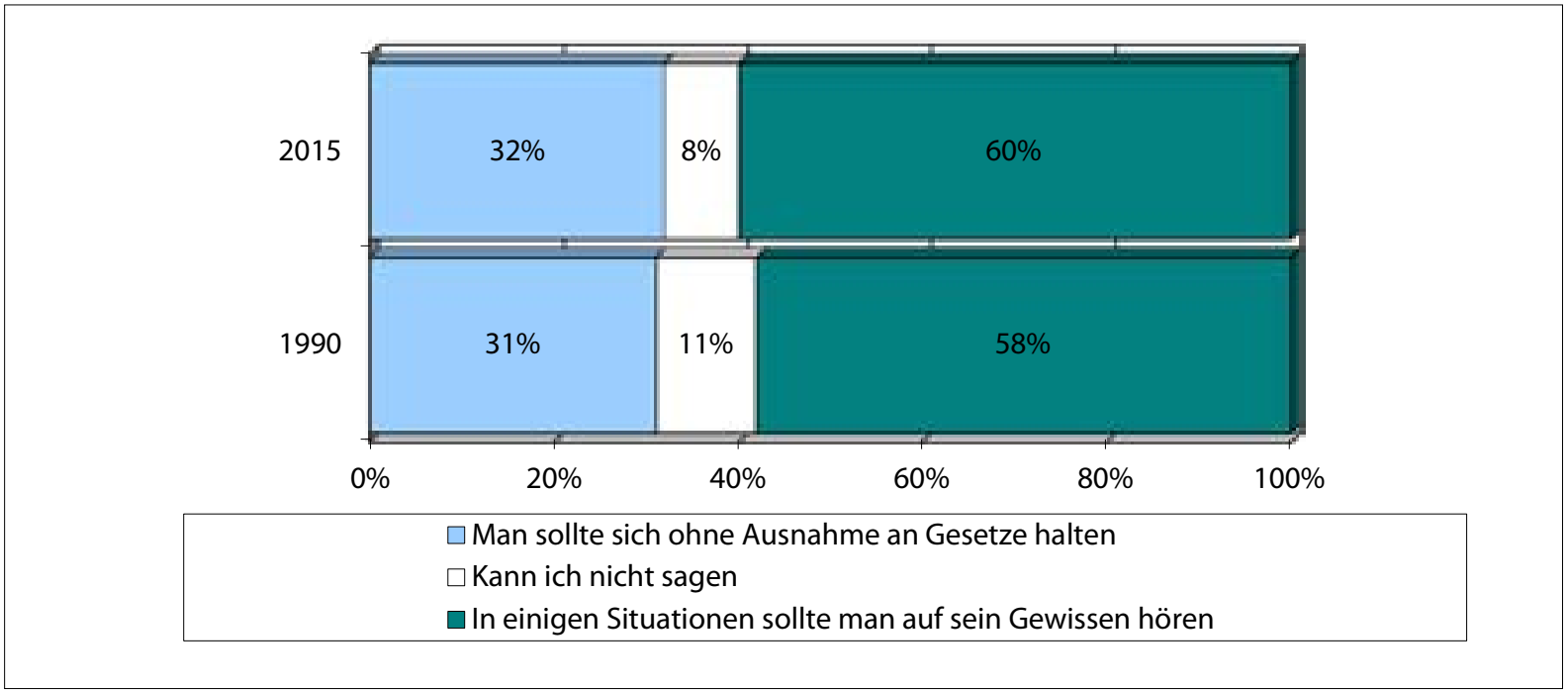

Quelle: Repräsentative Umfrage des Meinungsforschungsinstitut FOM im Zeitraum vom 14.-15. November 2015; N=1600; <http:// wciom.ru/index.php?id=236\&uid=115572>, 5. Februar 2016

\section{Staatsduma und Präsident: »Die Sonntagsfrage»}

Grafik 14: Welche der folgenden Aussagen gibt Ihre Haltung gegenüber den bevorstehenden Wahlen der russischen Staatsduma am besten wieder?

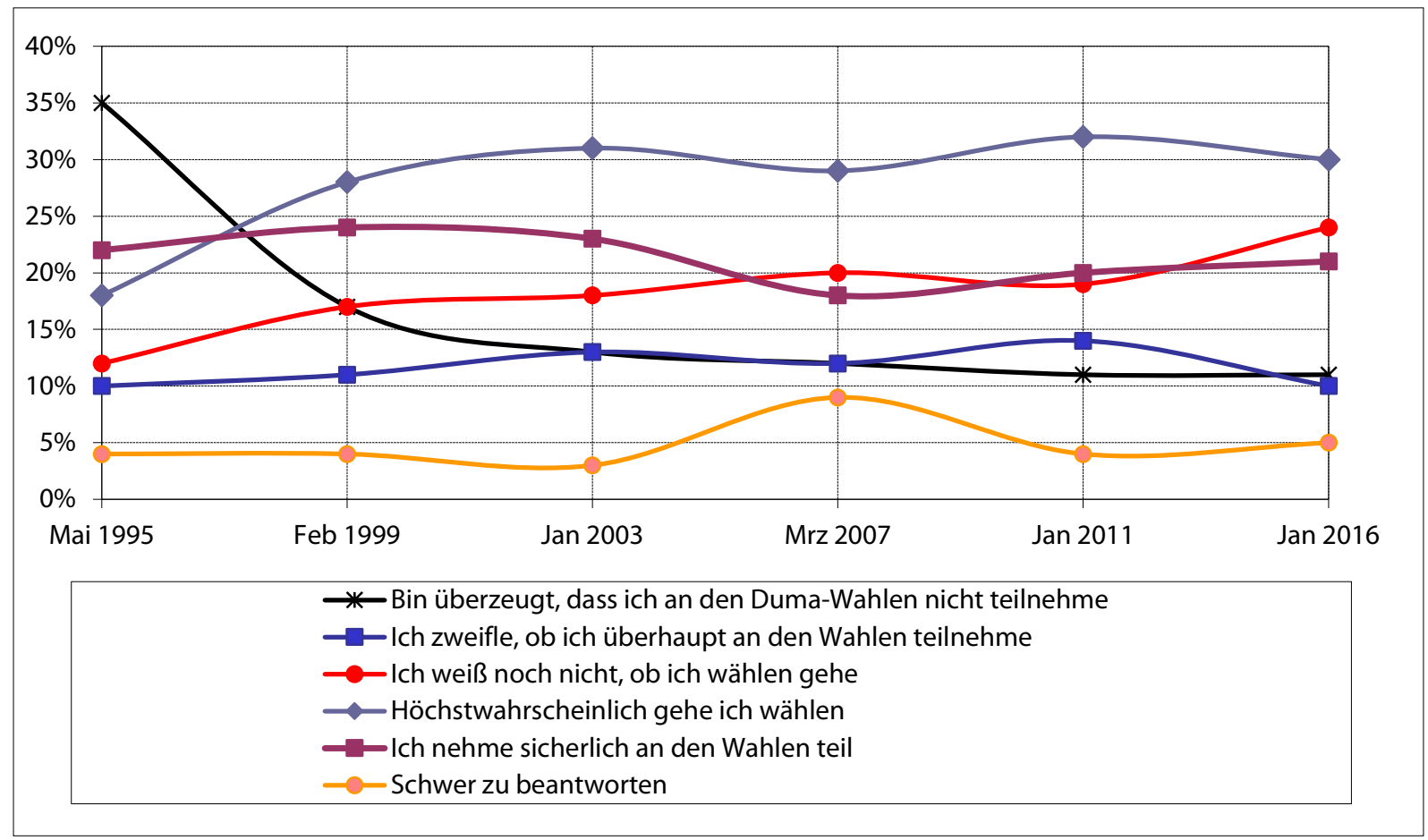

Quelle: Repräsentative Meinungsumfrage des Lewada-Zentrums im Zeitraum vom 22.-25. Januar 2016; N=1600; <http://www.le vada.ru/2016/02/10/elektoralnyj-rejting-partij-i-vozmozhnyh-kandidatov-v-prezidenty/>, 11. Februar 2016 
Grafik 15: Wenn am nächsten Sonntag Wahlen zur russischen Staatsduma wären, würden Sie daran teilnehmen und wenn ja, für welche Partei würden Sie stimmen? (geschlossene Frage)

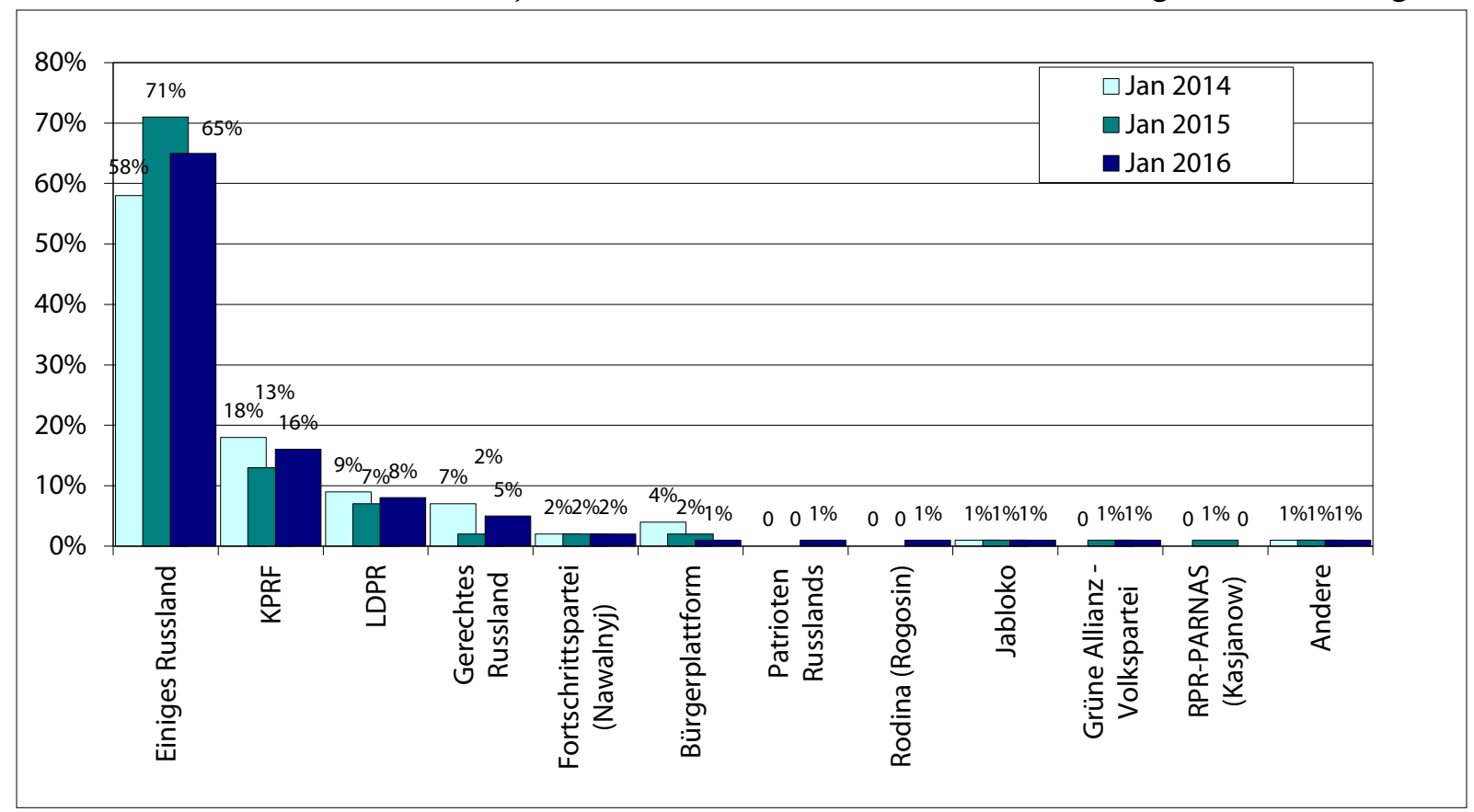

Quelle: Repräsentative Meinungsumfrage des Lewada-Zentrums im Zeitraum vom 22.-25. Januar 2016; N=1600; <http://www.le vada.ru/2016/02/10/elektoralnyj-rejting-partij-i-vozmozhnyh-kandidatov-v-prezidenty/>, 11. Februar 2016

Grafik 16: Wenn am nächsten Sonntag Präsidentschaftswahlen wären, würden Sie daran teilnehmen und wenn ja, für welchen der gegenwärtigen Politiker würden Sie stimmen? (Offene Frage)

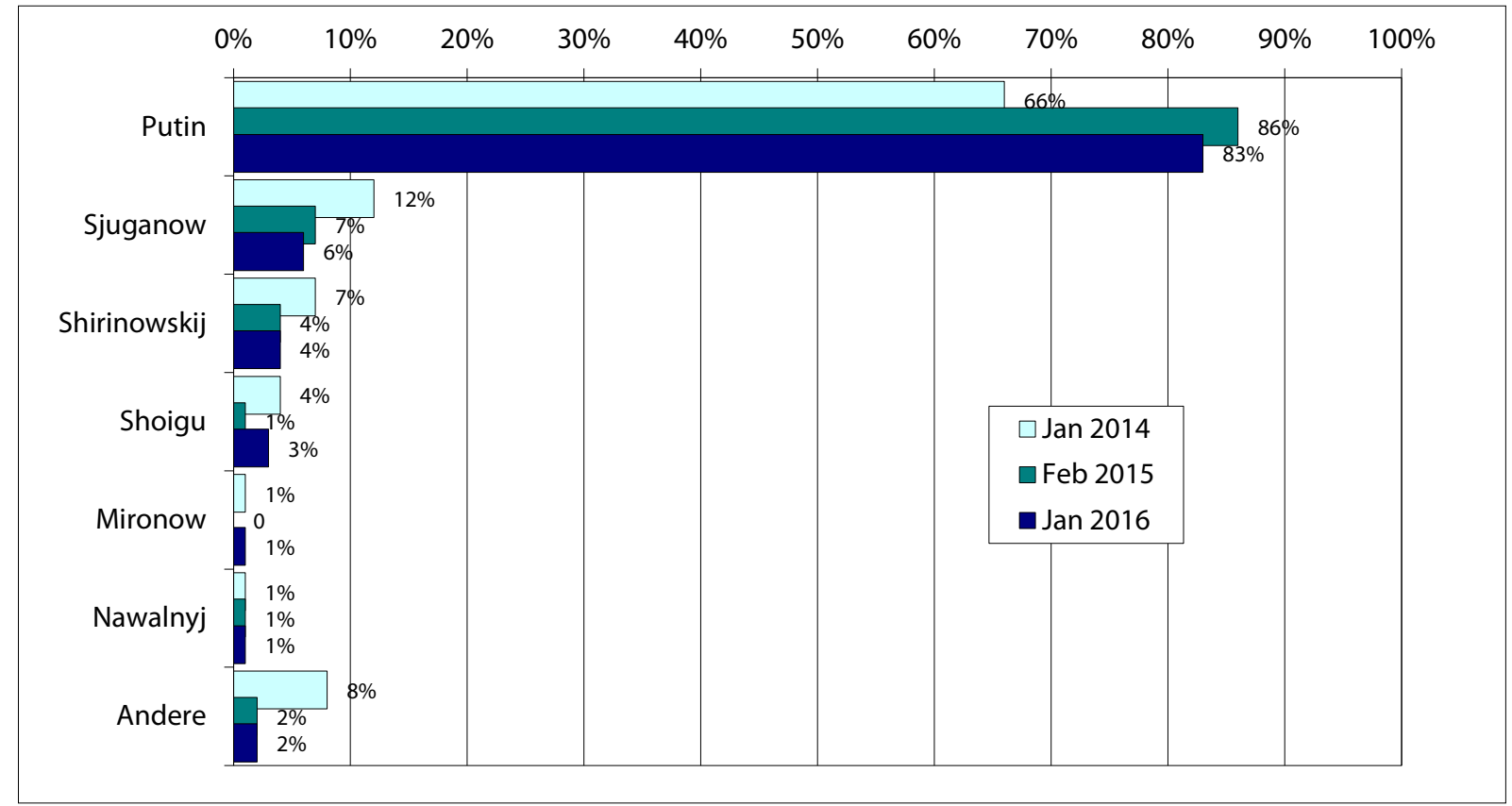

Quelle: Repräsentative Meinungsumfrage des Lewada-Zentrums im Zeitraum vom 22.-25. Januar 2016; N=1600; <http://www.le vada.ru/2016/02/10/elektoralnyj-rejting-partij-i-vozmozhnyh-kandidatov-v-prezidenty/>, 11. Februar 2016 


\section{5. - 18. Februar 2016}

\begin{tabular}{|c|c|}
\hline 05.02 .2016 & $\begin{array}{l}\text { Das russische Finanzministerium verschickt an } 25 \text { ausländische Banken die Aufforderung russische Staatsanlei- } \\
\text { hen auf den Markt zu bringen. Auf diesem Weg möchte Russland wieder Zugang zum internationalen Finanz- } \\
\text { markt erhalten. Es hatte zuletzt im September } 2013 \text { Anleihen platziert und war dann aufgrund der westlichen } \\
\text { Sanktionspolitik von den Kapitalmärkten weitgehend abgeschnitten. }\end{array}$ \\
\hline 05.02 .2016 & $\begin{array}{l}\text { Sitzung des russischen Sicherheitsrates. Themen sind unter anderem die geplante Privatisierung von Staatsbetrie- } \\
\text { ben und die Weiterentwicklung des Informations- und Koordinationszentrums von Russland, dem Irak, Syrien } \\
\text { und dem Iran in Bagdad. }\end{array}$ \\
\hline 06.02 .2016 & $\begin{array}{l}\text { US-Außenminister John Kerry fordert die russische Regierung auf, ihre Luftangriffe in Syrien einzustellen. Er } \\
\text { kritisiert vor allem die fehlende Präzision der russischen Luftschläge, die zu zahlreichen zivilen Opfern führt. } \\
\text { Während die USA, die Türkei und Frankreich vorgeschlagen haben, die Luftangriffe auszusetzen, erklärt Russ- } \\
\text { land, dass es die Angriffe auf IS-Stellungen fortführen wolle. }\end{array}$ \\
\hline 06.02 .2016 & $\begin{array}{l}\text { Finanzminister Anton Siluanow kündigt an, dass ab 1. April die Steuern für Benzin und Diesel angehoben wer- } \\
\text { den. Die Maßnahme soll zusätzliche Haushaltseinnahmen von bis zu } 80 \text { Mrd. Rubel (etwa } 940 \text { Mio. Euro) brin- } \\
\text { gen und werde für die Autofahrer nicht spürbar sein. }\end{array}$ \\
\hline 06.02 .2016 & $\begin{array}{l}\text { Anlässlich eines Parteitages der Regierungspartei »Einiges Russland« kommt es zum Personalwechsel im Partei- } \\
\text { vorstand und Führungsstab. Eine Reihe von Ministern sowie Gouverneuren, u. a. Finanzminister Anton Silua- } \\
\text { now sowie der stellvertretende Ministerpräsident Aleksandr Chloponin, müssen ihren Posten räumen. }\end{array}$ \\
\hline 08.02 .2016 & $\begin{array}{l}\text { Präsident Wladimir Putin trifft mit dem König von Bahrein, Hamad bin Isa Al Chalifa, in Sotschi zusammen. } \\
\text { Dieser befindet sich zu einem Arbeitsbesuch in Russland. }\end{array}$ \\
\hline 08.02 .2016 & $\begin{array}{l}\text { n Militärbezirk Süd findet eine unangekündigte Überprüfung der Gefechtsbereitschaft statt. Sie betrifft Luft- } \\
\text { ndetruppen und Transporteinheiten der Luftwaffe. }\end{array}$ \\
\hline 08.02 .2016 & $\begin{array}{l}\text { Der russische Inlandsgeheimdienst FSB nimmt in Jekaterinburg sieben mutmaßliche Mitglieder der Terrormiliz } \\
\text { "IS« fest. Die Verdächtigen sollen Anschläge mit selbstgefertigten Sprengkörpern in Moskau, St. Petersburg und } \\
\text { im Swerdlowsker Gebiet geplant haben. }\end{array}$ \\
\hline 08.02 .2016 & $\begin{array}{l}\text { er Republikchef von Tschetschenien Ramsan Kadyrow teilt im russischen staatlichen Fernsehen mit, dass in } \\
\text { rien tschetschenische Spezialeinheiten am Boden eingesetzt seien. Sie führten geheimdienstliche Operationen } \\
\text { rch, einige seien auch in die Strukturen des »IS « eingedrungen. }\end{array}$ \\
\hline 08.02 & $\begin{array}{l}\text { Bundeskanzlerin Angela Merkel kritisiert im Rahmen eines Treffens mit dem türkischen Ministerpräsidenten } \\
\text { Ahmet Davutoğlu die Operationen der syrischen Armee an der türkischen Grenze sowie deren massive Unter- } \\
\text { stützung durch die russischen Luftstreitkräfte. Sie wirft Russland vor, auf das Leiden von Tausenden von Zivi- } \\
\text { listen in den umkämpften Gebieten keine Rücksicht zu nehmen. }\end{array}$ \\
\hline 09.02 . & $\begin{array}{l}\text { If Anordnung des Moskauer Bürgermeisters Sergej Sobjanin werden in der Nacht zum 9. Februar in der gesam- } \\
\text { Stadt Kioske, Kleinläden und selbstgebaute Stände mit Bulldozern beseitigt. Als Begründung wird angegeben, } \\
\text { ss die Gebäude illegal errichtet worden seien und die Infrastruktur an Metro-Stationen beeinträchtigten. Die } \\
\text { haber reagieren mit Unverständnis, da die meisten Gebäude mit offizieller Genehmigungen betrieben wurden. }\end{array}$ \\
\hline $\begin{array}{l}\text { 09.- } \\
11.02 .2016\end{array}$ & $\begin{array}{l}\text { Die NATO-Verteidigungsminister vereinbaren bei einem Treffen in Brüssel, dass zum Zweck des Schutzes der Ost- } \\
\text { grenzen der Allianz die schnelle Einsatztruppe der NATO auf } 40.000 \text { Mann aufgestockt werden sollen. NATO- } \\
\text { Generalsekretär Jens Stoltenberg teilt zugleich mit, dass eine Wiederaufnahme des NATO-Russland-Rats auf } \\
\text { Botschafterebene erwogen werde. }\end{array}$ \\
\hline 09.02 .2016 & $\begin{array}{l}\text { onald Tusk, der Präsident der Europäischen Rates, erklärt, dass die russischen Bombardements in Syrien für } \\
\text { en neuerlichen Anstieg an Flüchtlingen verantwortlich seien, die Schutz in der Türkei und in Europa suchten. } \\
\text { as führe auch zur Schwächung der moderaten Kräfte in Syrien. }\end{array}$ \\
\hline 10.02 .2016 & $\begin{array}{l}\text { Präsident Wladimir Putin leitet eine Sitzung mit Regierungsmitgliedern. Es geht um die soziale und wirtschaftli- } \\
\text { che Entwicklung im Land, um die Medikamentenversorgung, die staatliche Unterstützung für Monostädte, den } \\
\text { Zugang zu staatlichen öffentlichen Aufträgen für kleine und mittelständische Unternehmen sowie die Umsied- } \\
\text { lung von Menschen aus beschädigten oder Notunterkünften. }\end{array}$ \\
\hline 10.02 .2016 & $\begin{array}{l}\text { Michail Kasjanow, der Vorsitzende der Oppositionspartei »PARNAS«, wird in einem Moskauer Restaurant ange- } \\
\text { griffen. Unbekannte, mutmaßlich tschetschenischer Herkunft, bewerfen den Politiker mit einer Torte. Der tschet- } \\
\text { schenische Republichef Ramsan Kadyrow hatte einige Wochen zuvor auf seinem Instagram-Account ein Bild von } \\
\text { Kasjanow gepostet, über das das Fadenkreuz eines Zielfernrohres gelegt war. }\end{array}$ \\
\hline 10.02 .2016 & $\begin{array}{l}\text { Das Oberste Gericht der Republik Tatarstan ordnet die Auflösung der Menschenrechtsorganisation "Agora" an. } \\
\text { Es ist das erste Mal, dass aufgrund des "NGO-Agentengesetzes» die Schließung einer NGO von einem Gericht } \\
\text { angeordnet wird. }\end{array}$ \\
\hline
\end{tabular}




\begin{tabular}{|c|c|}
\hline 10.02 .2016 & $\begin{array}{l}\text { Zwei ehemalige Manager der "Bank Moskaus« werden wegen Veruntreuung von einer Milliarde Rubel (ca. } 11 \\
\text { Millionen Euro) zu einer Haftstrafe von } 4 \text { bzw. 4,5 Jahren verurteilt. }\end{array}$ \\
\hline 10.02 .2016 & $\begin{array}{l}\text { Der Europäische Auswärtige Dienst teilt den Start einer neuen offiziellen russischsprachigen Webseite der EU } \\
\text { mit, die u. a. zum Ziel hat, Desinformation russischer Medien zu erfassen und durch Gegeninformation zu ent- } \\
\text { kräften. Zielgruppe sind nicht nur Bürger Russlands sondern russischsprachige Menschen auf der ganzen Welt, } \\
\text { insbesondere in Europa. }\end{array}$ \\
\hline 11.02 .2016 & $\begin{array}{l}\text { Das russische Justizministerium beantragt bei einem Moskauer Bezirksgericht die Auflösung der Wahlbeobach- } \\
\text { tungsorganisation »Stiftung `Golos« «. Die Organisation habe angeblich wiederholt Dokumente nicht fristgemäß } \\
\text { eingereicht und beanstandete Rechtsverletzungen nicht behoben, so die Begründung in der Klage des Ministeri- } \\
\text { ums. Golos kündigt an, die Entscheidung anfechten zu wollen. }\end{array}$ \\
\hline 11.02 .2016 & $\begin{array}{l}\text { Der Oppositionspolitiker Aleksej Nawalnyj kündigt in seinem Blog an, Klage gegen Präsident Wladimir Putin } \\
\text { bei einem Moskauer Gericht einreichen zu wollen. Als Begründung gibt er an, dass der Beschuldigte gegen das } \\
\text { föderale Anti-Korruptionsgesetz verstoßen habe. Es gehe dabei insbesondere um die Mitwisserschaft des Präsi- } \\
\text { denten bei zweifelhaften Geschäften seines Schwiegersohnes. }\end{array}$ \\
\hline 11.02 .2016 & $\begin{array}{l}\text { Die Außenminister Russlands und der USA, Sergej Lawrow und John Kerry, einigen sich mit dem UN-Gesand- } \\
\text { ten für Syrien Staffan de Mistura am Vorabend der Münchner Sicherheitskonferenz auf einen Plan zur Umsetzung } \\
\text { eines Waffenstillstandes in Syrien. Nach sechs Monaten innersyrischer Verhandlungen soll dann ein Abkommen } \\
\text { zur politischen Neuordnung Syriens abgeschlossen werden, gefolgt von Wahlen innerhalb eines halben Jah- } \\
\text { res. Alle Konfliktseiten sollen zudem jederzeit den Zugang humanitärer Hilfe für die Bevölkerung sicherstellen. }\end{array}$ \\
\hline 12.02 .2016 & $\begin{array}{l}\text { Der Leiter des Untersuchungskomitees Aleksandr Bastrykin äußert die Vermutung, dass der derzeitige Fall des } \\
\text { Rubels Resultat eines spekulativ bedingten Drucks auf die russische Währung sei. Im Einzelnen verdächtigt er } \\
\text { Großunternehmen illegal Insider-Informationen verbreitet zu haben. }\end{array}$ \\
\hline 12.02 .2016 & $\begin{array}{l}\text { Präsident Wladimir Putin leitet eine Sitzung der Militärisch-Industriellen Kommission. Erörtert werden die Bilanz } \\
\text { der militärischen Beschaffungsmaßnahmen } 2015 \text { und Perspektiven der Entwicklung des militärisch-industriel- } \\
\text { len Komplexes in Russland. }\end{array}$ \\
\hline 12.02 .2016 & $\begin{array}{l}\text { In der kubanischen Hauptstadt Havanna kommt es am Flughafen zu einem seit Langem geplanten Treffen zwi- } \\
\text { schen Papst Benedikt und Patriarch Kirill. Es ist das erste Treffen eines Oberhaupts der Römisch-katholischen } \\
\text { mit einem Oberhaupt der Russischen Orthodoxen Kirche, dauert zwei Stunden und endet mit der Unterzeich- } \\
\text { nung einer 30-Punkte-Erklärung }\end{array}$ \\
\hline 13.02 .2016 & $\begin{array}{l}\text { Interpol weist den Antrag des Moskauer Büros von Interpol ab, den ehemaligen Jukos-Vorsitzenden Michail Cho- } \\
\text { dorkowskij zur internationalen Fahndung auszuschreiben. Zunächst wird keine Begründung abgegeben, dann } \\
\text { wird erklärt, dass Interpol sich nicht in innere, vor allem nicht in politische, Angelegenheiten der teilnehmen- } \\
\text { den Staaten einmische. }\end{array}$ \\
\hline 13.02 .2016 & $\begin{array}{l}\text { Im Rahmen der Münchner Sicherheitskonferenz (12.-14. Februar) erklärt der russische Ministerpräsident Dmi- } \\
\text { trij Medwedew, dass der Dialog zwischen Russland und Europa fast gänzlich abgerissen sei und die Staaten im } \\
\text { Begriff stünden, »einen neuen kalten Krieg zwischen Russland und der NATO« zu beginnen. }\end{array}$ \\
\hline 13.02 .2016 & $\begin{array}{l}\text { Der ukrainische Präsident Petro Poroschenko beschuldigt auf der Münchner Sicherheitskonferenz seinen russi- } \\
\text { schen Amtskollegen Präsident Wladimir Putin den Versuch zu unternehmen, ein »alternatives Europa« zu grün- } \\
\text { den und dort Politiker, die seine Politik unterstützten, zu »Putinschen Soldaten« zu machen. Desweiteren erklärt } \\
\text { Poroschenko, dass es sich in der Ukraine und in Syrien nicht um Bürgerkriege handele, sondern jeweils um eine } \\
\text { Aggression Russlands gegenüber seinem Land und gegen die syrische Zivilbevölkerung. }\end{array}$ \\
\hline 13.02 .2016 & $\begin{array}{l}\text { Die Außenminister Russlands und der USA, Sergej Lawrow und John Kerry, kommen auf der Münchner Sicher- } \\
\text { heitskonferenz erneut zusammen. Thema sind die Vereinbarungen zu einem Waffenstillstand in Syrien. Die bei- } \\
\text { den Seiten einigen sich, dass es eine verstärkte militärische Zusammenarbeit geben müsse um die politischen Ver- } \\
\text { einbarungen aus den Arbeitsgruppen realisieren zu können. }\end{array}$ \\
\hline 14.02 .2016 & $\begin{array}{l}\text { Die Präsidenten Russlands und der USA, Wladimir Putin und Barack Obama, führen auf amerikanische Initia- } \\
\text { tive ein Telefongespräch mit dem Ziel die auf der Münchner Sicherheitskonferenz erreichten Vereinbarungen der } \\
\text { Syrien-Unterstützergruppe zu diskutieren. Konsens besteht darin, dass humanitäre Aspekte und das Erreichen } \\
\text { eines Waffenstillstandes unter bestimmten Bedingungen in den Vordergrund treten sollen. }\end{array}$ \\
\hline 14.02 .2016 & $\begin{array}{l}\text { Der Bürgermeister von Jekaterinburg, Jewgenij Rojsman, teilt mit, dass er den Vorsitzenden der Oppositionspar- } \\
\text { tei PARNAS, Michail Kasjanow unterstütze, insbesondere nach den zahlreichen Angriffen auf ihn. Es gehe aller- } \\
\text { dings nicht nur um Kasjanow, sondern darum, dass es eine Situation der Rechtlosigkeit in Russland gäbe. Dies } \\
\text { seien Vorbedingungen für einen Bürgerkrieg, so Rojsman. }\end{array}$ \\
\hline
\end{tabular}




\begin{tabular}{|c|c|}
\hline 14.02 .2016 & $\begin{array}{l}\text { Nachdem am Wochenende in den westlichen Gebieten der Ukraine Aktivisten begonnen hatten, die Weiterfahrt } \\
\text { von zahlreichen russischen LKWs in die EU zu blockieren, wird in der Ukraine darüber diskutiert, den Transit } \\
\text { russischer LKWs und Transporter gänzlich zu verbieten. In Russland wiederum, u. a. im Gebiet Brjansk, begin- } \\
\text { nen Aktivisten ebenfalls, ukrainische LKWs zu blockieren. }\end{array}$ \\
\hline 15.02 .2016 & $\begin{array}{l}\text { In der syrischen Provinz Idlib wird ein von der Organisation "Ärzte ohne Grenzen« betriebenes Krankenhaus } \\
\text { mit mindestens vier zielgerichteten Raketen aus der Luft angegriffen. } 50 \text { Menschen kommen ums Leben, zahlrei- } \\
\text { che werden verletzt. Das Krankenhaus ist vollständig zerstört. Die syrische Opposition macht Russland für den } \\
\text { Angriff verantwortlich, das syrische Regime hingegen die USA. }\end{array}$ \\
\hline 15.02.2016 & $\begin{array}{l}\text { Nach Angaben der russischen Gesundheitsministerin Veronika Skworzowa meldet Russland bei der Weltgesund- } \\
\text { heitsorganisation in Genf ein Patent auf einen Impfstoff gegen Ebola an. Das Moskauer Gamaleja-Forschungs- } \\
\text { institut für Epidemiologie und Mikrobiologie habe den zur Zeit effektivsten Impfstoff entwickelt, der unter dem } \\
\text { Namen "Gam-Evak« und "Gam-Evak Kombi« registriert und vorgestellt wird. }\end{array}$ \\
\hline 15.02.2016 & $\begin{array}{l}\text { Die russische Zentralbank rät den russischen Verbrauchern, in Krisenzeiten ihre Finanzmittel zu sparen und keine } \\
\text { Fernseher zu kaufen. Nach Angaben des stellvertretenden Vorsitzenden der Bank, Sergej Schwezow, sei das Wis- } \\
\text { sen über Finanzen in der Bevölkerung Russlands niedriger als in einigen Entwicklungsländern. }\end{array}$ \\
\hline 16.02 .2016 & $\begin{array}{l}\text { Russland einigt sich mit Saudi-Arabien sowie weiteren OPEC-Staaten (Katar und Venezuela) darauf, die tägli- } \\
\text { che Ölfördermenge auf dem Stand vom 11. Januar } 2016 \text { einzufrieren. }\end{array}$ \\
\hline 16.02 .2016 & $\begin{array}{l}\text { Nach Angaben eines Berichts der Menschenrechtsorganisation "Agora" und des russischen Verbandes der Inter- } \\
\text { netznutzer ist die Zahl der Fälle von Zensur und blockierten Internetseiten in Russland innerhalb eines Jahre um } \\
\text { ein Vielfaches angestiegen. Außerdem seien im letzten Jahr } 18 \text { Personen dafür, dass sie verbotene oder beanstan- } \\
\text { dete Inhalte im Internet geteilt oder öffentlich gemacht hatten, zu Haftstrafen ohne Bewährung verurteilt wor- } \\
\text { den (<https://meduza.io/static/internet_freedom-----2015.pdf }>\text { ). }\end{array}$ \\
\hline 16.02 .2016 & $\begin{array}{l}\text { Russland und die Ukraine einigen sich darauf, dass auf ihren jeweiligen Territorien blockierte Lastwagen bis zum } \\
\text { 25. Februar wieder ungehindert in ihre Heimatländer zurückkehren dürfen. Die Frage, ob der Transit russischer } \\
\text { und ukrainischer LKWs im jeweils anderen Land zukünftig möglich sein wird, ist weiterhin offen. }\end{array}$ \\
\hline 17.02.2016 & $\begin{array}{l}\text { Russland erhebt aufgrund der noch bestehenden Gasschulden in Höhe von } 3 \text { Milliarden Dollar vor dem High } \\
\text { Court in London Klage gegen die Ukraine. Nach Angaben des russischen Finanzministers Anton Siluanov habe } \\
\text { man lange genug, auch in Zusammenarbeit mit dem IWF, an einer außergerichtlichen Lösung gearbeitet, jedoch } \\
\text { ohne Erfolg. Es handele sich dabei um einen Präzedenzfall, so Siluanov. Auch Deutschland hatte in dem Schul- } \\
\text { denstreit versucht zu vermitteln. }\end{array}$ \\
\hline 17.02 .2016 & $\begin{array}{l}\text { Präsident Wladimir Putin empfängt den ungarischen Ministerpräsidenten Viktor Órban, der sich zu einem Arbeits- } \\
\text { besuch in Russland aufhält. Themen sind die bilaterale Zusammenarbeit, u. a. im Energiebereich . }\end{array}$ \\
\hline 18.02 .2016 & $\begin{array}{l}\text { Nach Angaben der internationalen Rating-Agentur Moody's verschlechtern sich die Prognosen für die russi- } \\
\text { sche Wirtschaft weiter. Gründe dafür seien der niedrige Ölpreis, die angespannte Haushalts- und Steuerpolitik } \\
\text { und Probleme bei der Regulierung der Schulden. Russlands BIP werde demzufolge } 2016 \text { um 2,5\% schrumpfen. }\end{array}$ \\
\hline
\end{tabular}

Sie können die gesamte Chronik seit 1964 auch auf <http://www.laender-analysen.de/russland/> unter dem Link »Chronik«lesen.

Die Russland-Analysen werden von Mangold Consulting GmbH unterstützt.

\section{MANGOLD}

C o n 5 \& 1 i i n $\mathrm{g}$

Herausgeber: Forschungsstelle Osteuropa an der Universität Bremen und Deutsche Gesellschaft für Osteuropakunde

Die Meinungen, die in den Russland-Analysen geäußert werden, geben ausschließlich die Auffassung der Autoren wieder. Abdruck und sonstige publizistische Nutzung sind nach Rücksprache mit der Redaktion gestattet. Redaktion: Hans-Henning Schröder (verantwortlich), Nadja Douglas Sprachredaktion: Hartmut Schröder Satz: Matthias Neumann

Russland-Analysen-Layout: Cengiz Kibaroglu, Matthias Neumann und Michael Clemens Alle Ausgaben der Russland-Analysen sind mit Themen- und Autorenindex archiviert unter www.laender-analysen.de Die Russland-Analysen werden im Rahmen eines Lizenzvertrages in das Internetangebot der Bundeszentrale für politische Bildung (www.bpb.de) aufgenommen. Die Russland-Analysen werden im Rahmen der Datenbank World Affairs Online (WAO) ausgewertet und sind im Portal IREON www.ireon-portal.de recherchierbar. ISSN 1613-3390 @ 2016 by Forschungsstelle Osteuropa, Bremen

Forschungsstelle 0steuropa • Publikationsreferat • Klagenfurter Str. 3 • 28359 Bremen • Telefon: + 49 421-218-69600 • Telefax: +49 421-218-69607 e-mail: publikationsreferat@osteuropa.uni-bremen.de•Internet-Adresse: http://www.laender-analysen.de/russland/ 


\section{Kostenlose E-Mail-Dienste der Forschungsstelle Osteuropa und ihrer Partner auf www.laender-analysen.de}

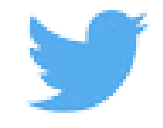

@laenderanalysen

Die Länder-Analysen bieten regelmäßig im kostenlosen Abonnement kompetente Einschätzungen aktueller politischer, wirtschaftlicher, sozialer und kultureller Entwicklungen in Ostmitteleuropa und der GUS. Sie machen das Wissen, über das die wissenschaftliche Forschung in reichem Maße verfügt, für Politik, Wirtschaft, Medien und die interessierte Öffentlichkeit verfügbar. Autoren sind internationale Fachwissenschaftler und Experten.

Die einzelnen Länder-Analysen werden von der Forschungsstelle Osteuropa an der Universität Bremen und der Deutschen Gesellschaft für Osteuropakunde jeweils mit unterschiedlichen Partnern und Sponsoren herausgegeben. Die Redaktionen der Länder-Analysen bestehen aus Wissenschaftlern mit langjähriger Forschungserfahrung.

Die Länder-Analysen bieten regelmäßig Kurzanalysen zu aktuellen Themen, ergänzt um Grafiken und Tabellen sowie Dokumentationen. Zusätzlich gibt es eine Chronik aktueller Ereignisse. Alle Länder-Analysen sind auch mit Archiv und Indizes online verfügbar unter <www.laender-analysen.de>.

\section{Belarus-Analysen}

Erscheinungsweise: zweimonatlich

Abonnement unter: <http://www.laender-analysen.de/belarus/>

\section{Caucasus Analytical Digest}

In englischer Sprache. Erscheinungsweise: monatlich

Abonnement unter: <http://www.css.ethz.ch/en/publications/cad.html>

\section{Polen-Analysen}

Erscheinungsweise: zweimal monatlich

Abonnement unter: <http://www.deutsches-polen-institut.de/newsletter/polen-analysen/>

\section{Russland-Analysen}

Erscheinungsweise: zweiwöchentlich

Abonnement unter: <http://www.laender-analysen.de/russland/>

\section{Russian Analytical Digest}

In englischer Sprache. Erscheinungsweise: zweimal monatlich

Abonnement unter: <http://www.css.ethz.ch/en/publications/rad.html>

\section{Ukraine-Analysen}

Erscheinungsweise: zweimal monatlich

Abonnement unter: <http://www.laender-analysen.de/ukraine/>

\section{Zentralasien-Analysen}

Erscheinungsweise: monatlich

Abonnement unter: $<$ http://www.laender-analysen.de/zentralasien/>

\section{Bibliographische Dienste}

Die Bibliographien informieren über englisch- und deutschsprachige Neuerscheinungen zu Belarus, Russland, Ukraine sowie zu den zentralasiatischen und kaukasischen Staaten. Erfasst werden jeweils die Themenbereiche Politik, Außenpolitik, Wirtschaft und Soziales.

Erscheinungsweise: viermal jährlich

Abonnement unter: <http://www.laender-analysen.de/bibliographies/belarus.php $>,<$ http://www.laender-analysen. de/bibliographies/russia.php>, <http://www.laender-analysen.de/bibliographies/ukraine.php $>$, <http://www.laenderanalysen.de/bibliographies/caucasus_ca.php> 